\title{
Microwave Fixation and Localization of Calcium in Synaptic Terminals and Muscular Cells by Electron Probe X-Ray Microanalysis and Electron Energy-Loss Spectroscopy Imaging
}

\author{
Vinci Mizuhira $^{1}$, Hiroshi Hasegawa ${ }^{2}$ and Mitsuru Notoya ${ }^{2}$ \\ ${ }^{1}$ Medical Research Institute, Tokyo Medical and Dental University, Bunkyoku, Tokyo 113 and ${ }^{2}$ Developmental \\ Research Laboratories, Shionogi \& Co., \& Ltd., Futabacho, Toyonaka, Osaka 561
}

Received for publication March 27, 1997

\begin{abstract}
The distribution of calcium ions in the rat brain synaptic terminals, in their synaptic vesicles, membranes and mitochondria; and in the sarcoplasmic reticula, mitochondria and their endosacs of skeletal or cardiac muscle cells, and in the caveolae of endothelial cells of blood capillaries was investigated with a two-step inorganic chemical precipitation method using potassium oxalate followed by potassium antimonate.

During the process, calcium ions were precipitated with potassium oxalate containing aldehyde fixative as an insoluble precipitate of calcium oxalate under simultaneous computerized microwave irradiation fixation. Then the precipitates were chemically changed to calcium antimonate during the postfixation procedure with an osmium tetroxide fixative containing potassium antimonate. The chemical natures and elemental binding ratios of this precipitate of calcium and antimony in the tube test and in sections were investigated by computerized electron probe $X$-ray

that calcium ions exsisted in the site of precipitate.

Electron energy-loss spectroscopy imaging showed the distribution of digital net calcium images at electron microscopic resolution. Calcium exsisted in the nerve terminals, synaptic vesicles, mitochondria and synaptic membranes; in the skeletal and cardiac muscular endosacs of sarcoplasmic reticula, mitochondria, and in the endocytotic vesicles of cardiac sarcoplasmic membranes, or in the caveolae of blood vessel capillary endothelial cells.

High magnification 0 -loss images and EELS spectra confirmed differences in the fine precipitates in a section, as most of the precipitates were $\mathrm{Ca}$-antimonate showing a clot of fine needle-like crystals, but in some cases we found antimonic acid showing an electron opaque foamy spot, or just contamination with an irregularly shaped homogeneous opacity. They were found mixed together, and it was not easy to differentiate them under EDX analysis.
\end{abstract} microanalysis using an energy dispersive type X-ray detector (EDX) and electron energy-loss spectroscopy (EELS) imaging. The EDX analyzed chemical nature and calculated values of precipitates, in both atomic binding ratios (AT, \%) and molecular weight ratios (WT, \%), were exactly the same as those of the theoretical calculated values based upon the chemical formula of calcium antimonate. The data indicated

Summarized data were reported in the 10th International Congress on Histochemistry and Cytochemistry, Kyoto, Japan, 1996 [24] and XXIth International Congress \& International Academy of Pathology, and 12th World Congress on Academy of Enviromental Pathology, Budapest, Hungary, 1996 [26].

Key words: Calcium ion, Synapse, Muscular cells, EDX/EELS analysis, Microwave fixation

Selected by "The 10th International Congress of Histochemistry and Cytochemistry" held in Kyoto, Japan on Aug. 18-23, 1996.

Correspondence to: Vinci Mizuhira, Prof. Emeritus, Tokyo Medical and Dental University, Yushima, Bunkyoku, Tokyo 113, Japan.

Present Address: 3-20-13, Kichijoji-Honcho, Musashino City, Tokyo 180, Japan.

\section{Introduction}

Microwave irradiation (MWI) of biomedical specimens has been reported since Mayers in 1970 [8] and a handbook edited by Kok and Boon in its 3rd edition in 
1992 [5]. Mizuhira et al. [12-21, 26] used a household microwave oven for fixation and staining, with excellent results. They investigated the mechanism of fixation with MWI, i.e., why MWI enabled the aldehyde to penetrate into the tissue block so quickly and homogeneously within a few seconds, with thaw mount cryomicroautoradiography using ${ }^{3} \mathrm{H}$-formalin as a tracer. MWI treatment led to the development of prominent developed silver grains distributed homogeneously in thaw mount cryosections, but not in conventional immersion fixed sections [12, 17, 19]. They also studied why MWI enabled the staining materials, uranyl acetate and lead hydroxide solutions, to penetrate into even thicker sections quickly and homogeneously by computerized EDX analysis which compared the characteristic X-ray pulse intensity ratios of $\mathrm{U} \cdot \mathrm{L} \alpha$ and $\mathrm{Pb} \cdot \mathrm{M} \alpha[12,16-19,24-26]$. They described the application of MWI to conventional histology, cytology, histo-cytochemistry including immunocytochemistry, micro- and electron microscopic autoradiography, and the distribution of ionic elements, such as calcium, using computerized electron probe X-ray microanalysis (EDX) and electron energy-loss spectroscopy (EELS) imaging [1226]. Using tannic acid (TA) with aldehyde fixative, good, rapid fixation was obtained when MWI was used [11-21]. Combined TA/MWI fixation and double electron staining/MWI methods have produced excellent fixation and staining of proteins and small, soluble peptides, and even enkephaline [11-19, 24-26]. For example, it is easy to obtain opening images of nerve synaptic vesicles at the presynaptic membranes, and the ATP-synthesize particles on the surface of the mitochondrial cristae, ribosomes and associated messenger RNA filaments, cytoplasmic skeletons, and connections between the micro- or neurotubules and the outer surface of the mitochondria could often be observed [11-19, 24-26].

The distribution of calcium ions $\left(\mathrm{Ca}^{2+}\right)$ in living tissue and cells can be studied by various methods under the electron microscope. (1) Fresh tissue can be rapidly frozen, cut into ultrafrozen sections, and then analyzed by EDX or EELS imaging; (2) fresh tissue blocks can be freezesubstituted with cooled acetone or ether, then analyzed with EDX or EELS, after embedding in Epon or a low viscosity resin, such as Spurr; (3) inorganic chemical reagents can produce insoluble and electron-opaque fine precipitates with $\mathrm{Ca}^{2+}$ ions in the cell, and then they can be analyzed with EDX or EELS; (4) the chemical nature of the precipitates can be confirmed by EDX, EELS or by calcium subtraction with EDTA or EGTA solution [12, 19, 21-26]. The reliability of method (4), especially with EDTA or EGTA method is low. Methods (1) and (2) [9, 10] seem good theoretically, but they have, especially method (1), some technical drawbacks. We have used method (3) combined with microwave stimulated fixation. After the fixation, the tissue blocks were analyzed with computerized EDX or EELS imaging [20-26].

We devised a new technique to detect the location of $\mathrm{Ca}^{2+}$ ions in tissue and cells using a two-step fixation method, i.e., the use of aldehyde fixative containing potassium (K) oxalate with microwave irradiation, followed by osmium tetroxide containing potassium (K) antimonate.

$\mathrm{K}$-antimonate used to be called potassium pyroan-

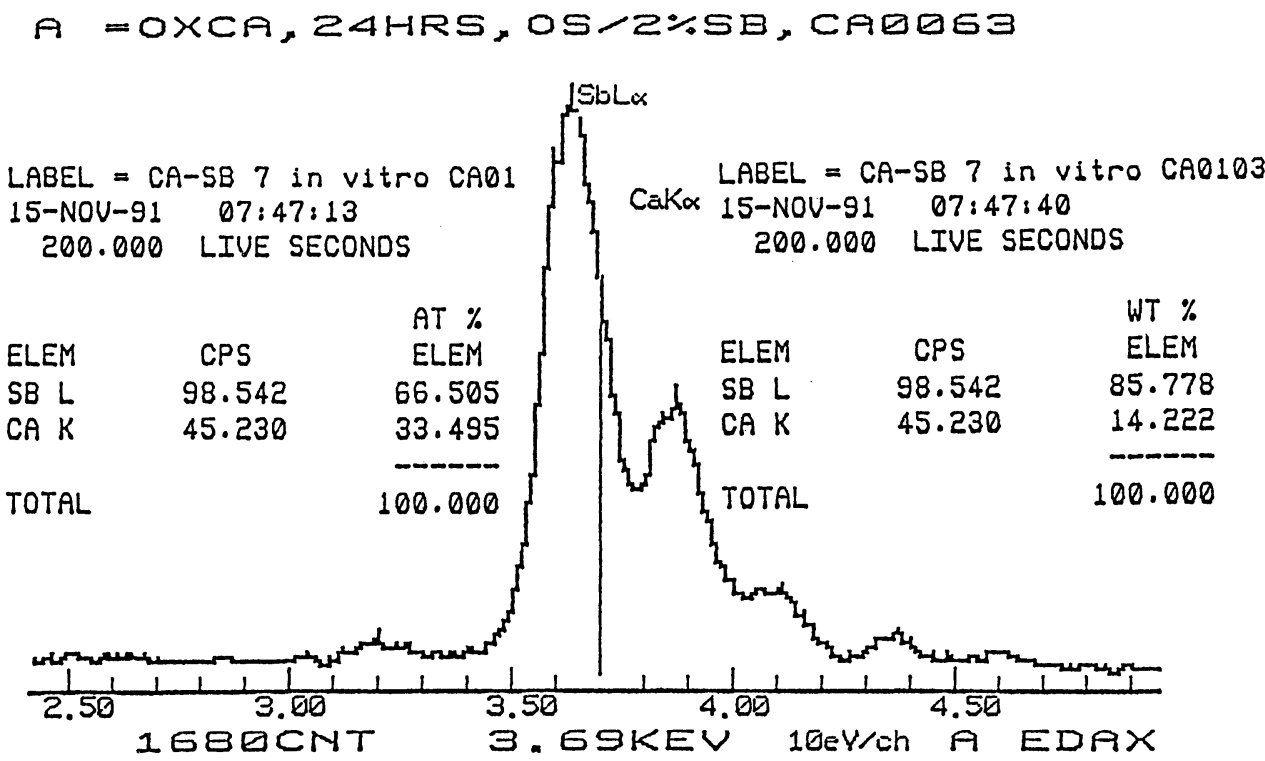

Fig. 1. A typical EDX-spectrum obtained from crystals of calcium antimonate. The crystals were obtained from calcium oxalate after being substituted with potassium antimonate solution for $24 \mathrm{hr}$ in a glass tube. Calculated values of atomic binding ratios (AT, \%) and molecular weight ratios (WT, \%) in both calcium (Ca) and antimony (Sb) were the same as the theoretical values [12, 19, 21], as shown in the figure. If the ionic balance between the calcium and antimonic acid is different, analyzed data will be different [35]. Japan Philips EDAX PV$9800 / \mathrm{JEOL}-1200 \mathrm{EX} / \mathrm{STEM}$, at $60 \mathrm{kV} / 200 \mathrm{sec}$. 
timonate $\left(\mathrm{K}_{3} \mathrm{H}_{2} \mathrm{Sb}_{2} \mathrm{O}_{7} \cdot 4-6 \mathrm{H}_{2} \mathrm{O}\right)$, but this theory is now obsolete. Present knowledge has it that the chemical is not K-pyroantimonate, but K-antimonate, $\mathrm{K}\left[\mathrm{Sb}(\mathrm{OH})_{6}\right]$. Chemical reactions with some ions occur as a form of $\mathrm{K}$-antimonate, and this chemical formula coincides well with the analytical data of EDX. Therefore, we use the designation K-antimonate.

During the postfixation procedure, Ca-oxalate fine precipitate in a cell is replaced completely by $\mathrm{Ca}$ antimonate with $\mu \mathrm{M}$ sensitivity $[12,15-21,24-26]$. We reported the distribution of calcium in synaptic terminals, endosacs or mitochondria of skeletal and heart muscle cells by computerized EDX, treated after the 2-step chemical fixation method, and showed that the measured values of precipitates in a cell were the same as those derived from theoretically calculated values based on the chemical formula:

$\mathrm{Ca}\left[\mathrm{Sb}\left(\mathrm{OH}_{6}\right)\right]_{2}$, which is,

atomic binding ratio $(\mathrm{AT}, \%)$ of $\mathrm{Ca}: \mathrm{Sb}$ is $1: 2=$ 33.3 : 66.7\%; molecular weight ratio (WT, \%) is 40.08 : $2(121.7)=14.1: 85.9 \%$ (see, Fig. 1) [12-19, 21-26].

The values should be changed depending upon the ionic balance between the elements. For example, in the early stage of the calcifying tissue, fewer Ca-ions appeared, and the ratio of $\mathrm{Ca}$ to $\mathrm{Sb}$ was very small, and calcification progressed, only $\mathrm{Ca}$ was detected in computerized EDX analysis [35].

However, we could not obtain an image of calcium distribution with the EDX method [9, 10, 20-26], so we tried to get better results with EELS imaging [20-26].

We applied EELS imaging for the detection of calcium ions in rat central nerve synaptic terminals, and in skeletal and cardiac muscle cells by cutting $30 \mathrm{~nm}$ ultrathin sections from the tissue blocks that were used for the EDX analysis, after chemical and MWI tissue fixation. Thus we were able to localize calcium ions in their fine stuctures as fine calcium $\left(\mathrm{Ca} \cdot \mathrm{L}_{2,3}\right)$ and antimony $\left(\mathrm{Sb} \cdot \mathrm{M}_{4,5}\right)$ images superimposed on energy filtered spectroscopic, dark fieldlike (about $250 \mathrm{eV}$ ) images [20-26].

In this report, we discuss the distribution of calcium ions in rat brain synaptic terminals, and in skeletal and cardiac muscle cells, and caveolae in the endothelial cells of blood vessel, as seen with EELS imaging as compared with data from EDX. We also discuss the problems of tissue fixation with MWI, and calcium ion detecting methods by the 2-step inorganic chemical precipitation.

\section{Materials and Methods}

Materials and sampling procedures were almost the same as described in previous reports [12, 19, 21, 25, 26], and can be summarized as follows.

As experimental animals, male rats (Sprague-Dawley) were used. For control observations, whole brains (medulla oblongata, cerebellum and cerebrum), intercostal muscle as skeletal muscle, and cardiac muscle were removed as quickly as possible from anaesthetized rats, cut into small pieces in a drop of fixative on a plastic sheet, and then immersed in the fixative (details in Table 1-A) in small vials. Brains were cut in half or one-quarter, and immersed in fixative in a small beaker. The sample-containing vials or beaker were subjected to microwave irradiation (MWI) in a water bath for 30-35 sec at room temperature for both conventional light and electron microscopy (microprocessed household microwave oven or Nisshin EM MWF- 2,500W/100V was used) $[12,15-19,21,24-$ 26]. Brain tissue was cut into small pieces on a plastic plate after microwave stimulation, and then the pieces were returned to the fixative in small vials in a water bath, and subjected to MWI for an additional 30-35 sec again at room temperature $[12,15,16,21,25,26]$. They were left in the fixative after MWI for about $60 \mathrm{~min}$ at room temperature $[12,19,21,24-26]$.

Post-fixation was performed with $1 \%$ osmium tetroxide in a buffer solution as shown in Table 1-B. After dehydration in a graded ethanol series, the blocks were embedded in Epon, and ultrathin sections were cut, mounted on copper grids, and double-stained with uranyl acetate and lead hydroxide solution under MWI for electron microscopy, or embedded in Technovit resin for light microscopy, cut into $1 \mu \mathrm{m}$ sections with glass knives, and stained with methylene blue/acid fucsin [12-14, 19]. Then the samples were compared.

As mentioned above, ultrathin sections for conventional electron microscopy were double-electron stained with uranyl acetate and lead hydroxide solution under the computer-controlled MWI at $60-70^{\circ} \mathrm{C}$ for about $5-7 \mathrm{~min}$ $[12,18,19,21,24,26]$.

To detect calcium ions in the nerve and muscle tissues, we used the method reported previously as outlined in Table $2[12,15-19,21-26,35]$. The tissue blocks were microwaved in a fixative containing potassium oxalate for

Table 1. Fixation for Conventional Light and Electron Microscopy

A. Fixation with Microwave Irradiation (MWI)

$2 \%$ paraformaldehyde (dissolve just before use)

$0.5 \%$ glutaraldehyde

$0.1 \mathrm{M}$ sodium cacodylate buffer (for kidney, $0.075 \mathrm{M}$ )

2-3 $\mathrm{mM}$ of $\mathrm{CaCl}_{2}$ and 1-2 $\mathrm{mM}$ of $\mathrm{MgCl}_{2}$

0.1\% tannic acid (Merck, add just before use), at pH 7.2-7.4

MWI performed for $30-35 \mathrm{sec}$ at room temperature, in a water bath. After MWI, tissue blocks are left in the fixative for about $60 \mathrm{~min}$ at room temperature.

B. Post-fixative for Electron Microscopy

$1 \%$ osmium tetroxide

0.1 $\mathrm{M}$ sodium cacodylate buffer at $\mathrm{pH} 7.2-7.4$

Immerse for $60 \mathrm{~min}$ at room temperature. Embed in Epon after standard dehydration. 
30-35 sec at room temperature. The tissue blocks were left in the fixative for $60 \mathrm{~min}$ at room temperature (Table 2) $[12,16,19,21,26]$. The amount of oxalic acid added to the fixative was found to be very important in step A of Table 2. A final concentration of about $30-40 \mathrm{mM}$ oxalic acid yields good results for brain and nerve tissue, and 40$60 \mathrm{mM}$ is acceptable for muscle tissues or others $[12,16$, 19, 21, 24-26, 35]. The first step of this MWI fixation for calcium ion detection allows rapid homogeneous penetration of the oxalic acid into the tissue blocks, where the oxalic acid can penetrate with a fixative within a short time. On the other hand, detection of calcium ions by conventional immersion fixation leads to uneven infiltration, irregular precipitates, and destruction of ultrastructures. The process also takes longer than when MWI is used [12, 21, 25].

Post-fixation was done with osmium tetroxide containing $\mathrm{K}$-antimonate (Table 2). In this process, we do not use a buffer solution, but $\mathrm{pH}$ is adjusted with a small amount of acetic acid or $1 / \mathrm{N} \mathrm{KOH}$ at $\mathrm{pH} 7.2$, at room temperature (Table 2B). In this process, we recommend less $\mathrm{K}$ antimonate for post-fixation than that reported previously $[12,19,21,25,27]: 1-1.5 \%$ is best. Less oxalic acid (30$40 \mathrm{mM}$, for nerve tissues, and $40-60 \mathrm{mM}$ for muscle tissues), and $\mathrm{K}$-antimonate (1-1.5\%), as described above, kept ultrastructures intact and prevented loss of calcium ions during the process $[12,21,25,35]$.

Table 2. Method of Detecting Calcium Ions in Tissue and Cells

\section{A. Fixation}

$2 \%$ paraformaldehyde

$0.5 \%$ glutaraldehyde

$0.1 \mathrm{M}$ sodium cacodylate buffer at $\mathrm{pH} 7.2$

$0.1 \%$ tannic acid (add just before use)

$30-90 \mathrm{mM}$ of potasium (K-) oxalate (usually, $40-60 \mathrm{mM}$ is used for skeletal muscle, cardiac muscle, etc., and 30-40 $\mathrm{mM}$ for central nervous tissue)

MWI for 30-35 sec, at room temperature (maximum temperature was controlled at $40^{\circ} \mathrm{C}$ with a computer control box) in a water bath. Tissue blocks are left in the same fixative for $60 \mathrm{~min}$ at room temperature.

B. Post-fixation

$1 \%$ osmium tetroxide

$1-1.5 \% \mathrm{~K}$-antimonate, $\mathrm{pH}$ adjusted with a small amount of

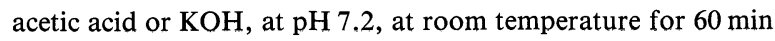
(buffer solution is not used).

During the procedure, Ca-oxalate is replaced gradually by antimonic acid, and finally $\mathrm{Ca}$-antimonate remains in the tissue and cells (chemical replacement or substitutioin), without any loss of calcium. The sensitivity for calcium ions is calculated to be about a few $\mu \mathrm{M}[12]$.

Tissue blocks are embedded in Epon, after standard rinsing and dehydration procedures.
After post-fixation, the tissue blocks were dehydrated in an ethanol series and embedded in Epon or Spurr resin. Ultrathin sections for EDX analysis were mounted on nylon grids, and analyzed with a computerized EDAXPV-9800 (Japan Philips) fitted to a JEM-1200EX transmission electron microscope (TEM) using scanning (SEM) and scanning transmission (STEM) mode apparatus with a $60 \mathrm{kV}$ accelerating voltage. Characteristic X-ray pulses of the calcium $(\mathrm{Ca} \cdot \mathrm{K} \alpha)$ and antimony $(\mathrm{Sb} \cdot \mathrm{L} \alpha)$ obtained from the precipitates were counted for $200 \mathrm{sec}$ in a selected area $(200 \times 200 \times 100 \mathrm{~nm})$ in the STEM mode under the same magnification with an energy dispersive (EDX) type X-ray detector. EDX analysis was performed after 1-2 hr strict calibration of the X-ray detector with standard crystals of Ca-antimonate, $\mathrm{KCl}, \mathrm{CaCl}_{2}, \mathrm{Si} \cdot \mathrm{K}$ and copper grid $(\mathrm{Cu} \cdot \mathrm{K} / \mathrm{L})$, and finally, calibration was centered on the $\mathrm{Cl} \cdot \mathrm{K}, \mathrm{K} \cdot \mathrm{K}, \mathrm{Ca} \cdot \mathrm{K}$ and $\mathrm{Sb} \cdot \mathrm{L}[12,19,21,25,26,35]$. The chemically and theoretically calculated values of $\mathrm{Ca}$ antimonate are shown in the Figure 1 spectrum. The analyzed values of atomic binding ratios (AT, \%) of $\mathrm{Ca}: \mathrm{Sb} \fallingdotseq 33.3: 66.7$, and elemental molecular weight ratios (WT, \%) $\fallingdotseq 14.1: 85.9$, agreed completely with those of the standard sample and the theoretical calculated values of the chemical formula of calcium antimonate, $\mathrm{Ca}\left[\mathrm{Sb}(\mathrm{OH})_{6}\right]_{2}[12,19,21,24-26,35]$.

As a control experiment for calcium ion detection by EDX analysis, sections which were treated with a 2-step chemical fixation method on nylon grids were floated on $10 \mathrm{mM}$ EDTA or EGTA for $1 \mathrm{hr}$ at $60^{\circ} \mathrm{C}$ as described in previous reports $[12,19,21,25]$. During the procedure, fine Ca-antimonate precipitates dissolved out of the sections, and no $\mathrm{Ca} \cdot \mathrm{K} \alpha$ and $\mathrm{Sb} \cdot \mathrm{L} \alpha$ characteristic X-ray spectra could be detected by EDX analysis [21].

For the EELS analysis, we used the same tissue block as for the EDX analysis. Thinner ultrathin sections, $30 \mathrm{~nm}$, were cut and mounted on copper 400 grid mesh for Zeiss EM-902A EELS electron microscope [9, 10, 20, 2226], or thicker sections, 50-70 nm, cut for a JEM2010F/GIF (F: field emission illumination; GIF: Gatan Image Filter, JEOL Co., Ltd./Gatan) electron microscope at $200 \mathrm{KV}$ accelerating voltage, without electron staining or carbon evaporation for protection from electron beam damage. The former thinner sections were observed under a Zeiss EM/CEM-902A/IBAS electron microscope (Image analyzer) at $80 \mathrm{kV}$ accelerating voltage with an electrostatic prism/mirror/prism type energy filter (Niigata University) and the latter thicker sections were viewed with a JEM-2010F/GIF (with image analyzing system) at 200 KV (JEOL Co. Ltd., Application Lab.).

First, the energy filtered electron images, at 0-loss image (Figs. 15C, 19A) and about $250 \mathrm{eV}$ with a dark field-like (electron energy spectroscopic) image as shown in Figs. 16 and 18A. This dark field-like image does not show elemental images, but it has very good electron contrast showing the same resolution as the original transmission electron microscopy even in unstained ultrathin sections. This dark field-like image was stored on a floppy 
disk as a digital image. Next, EELS spectra which are needed to detect the elements were recorded from the section, and then the presence of the expected elements was confirmed; in this experiment, the expected elements were $\mathrm{O} \cdot \mathrm{K}$ (maximum peak value, $544 \mathrm{eV}) ; \mathrm{Ca} \cdot \mathrm{L}_{2,3}(355 \mathrm{eV})$ and $\mathrm{Sb} \cdot \mathrm{M}_{4,5}(590 \mathrm{eV})$ (Fig. 15A, D). Analyzed spectra were recorded on the disk. The expected elemental net EELS image, for example, in the case of $\mathrm{Ca} \cdot \mathrm{L}$, can be obtained as follows: maximum spectrum peak value of $\mathrm{Ca} \cdot \mathrm{L}$ is 355 $\mathrm{eV}$, and the background image of $\mathrm{Ca} \cdot \mathrm{L}$ is selected above or below the maximum value, 341 or $305 \mathrm{eV}$. The net $\mathrm{Ca} \cdot \mathrm{L}$ EELS image is obtained by subtracting the background image from the maximum spectrum with an image analyzer such as the CEM-902A at $80 \mathrm{KV}$ accelerating voltage or IBAS (Zeiss, image analyzer), or JEM-2010F/GIF with image analyzsing system at $200 \mathrm{KV}$ (Figs. 17, 18B, 19B, 20A, B, 21A).

Special care is needed when superimposing two images during the background subtraction with a computer. The net $\mathrm{Ca} \cdot \mathrm{L}$ image is recorded again on a disk as a digital
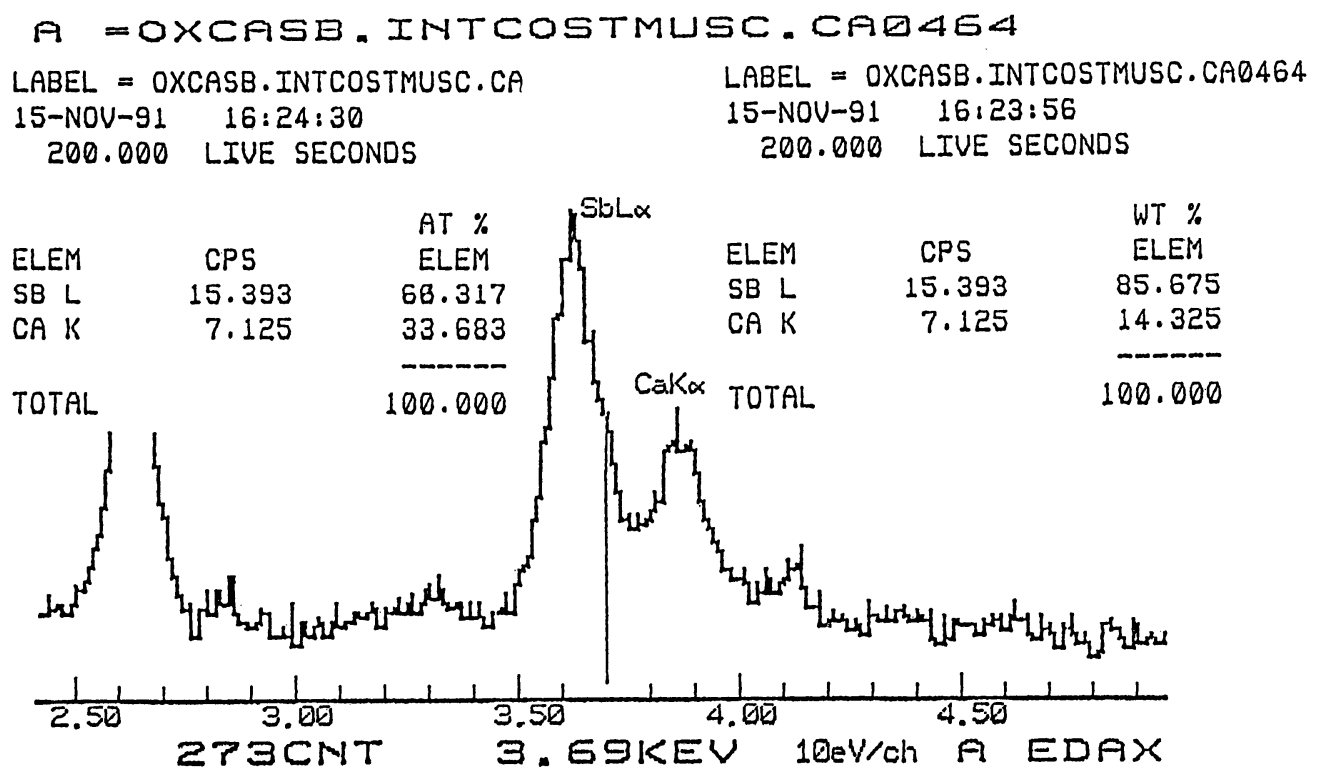

Fig. 2. EDX analyzed spectrum was obtained from the precipitates in the endosac of rat intercostal muscle. The data indicate that the precipitates are Ca-antimonate, and computer analyzed values of AT and WT (\%) in both $\mathrm{Ca}$ and Sb were the same as those of the standard sample, as shown in Fig. 1. Calcium ions exist in the endosac.

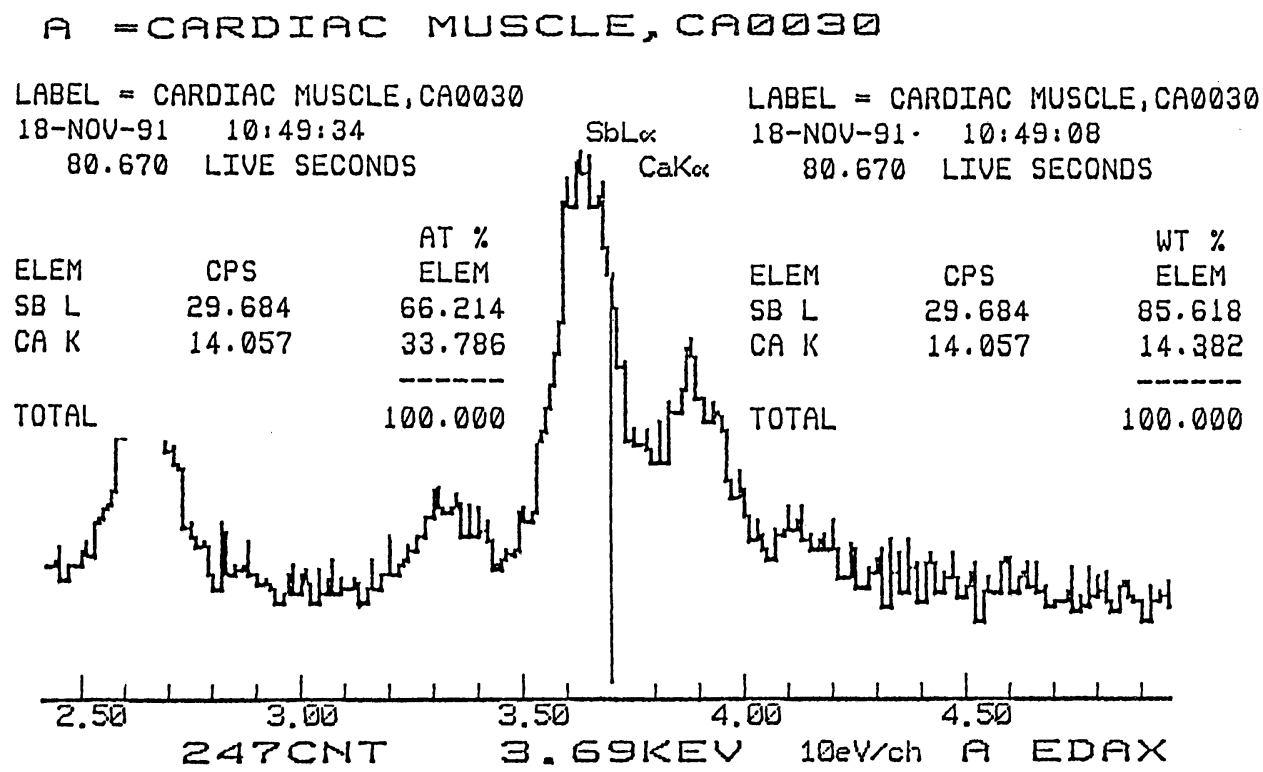

Fig. 3. EDX analyzed spectrum was obtained from the precipitates in the sarcoplasmic reticulum of a rat cardiac muscle. Spectrum and computer calculated values are those of the standard sample of Ca-antimonate, as shown in Fig. 1. 
image, and the image is color coded artificially by the computer. In our case, $\mathrm{Ca} \cdot \mathrm{L}$ is shown as light blue (Figs. 17, 18B, 19B, 20B, 21A), Sb.M is light green (Figs. 18C, 19C, 20C, 21B), and $\mathrm{O} \cdot \mathrm{K}$ is yellow (Fig. 19D) [10, 20, 2225]. Finally, the net elemental images are superimposed on the original dark field-like electron energy-spectroscopic images for a good understanding of the sites of elemental distribution on the ultrastructures (Figs. 17, $18 \mathrm{~B}, \mathrm{C}, 20 \mathrm{~B}, \mathrm{C}, 21 \mathrm{~A}, \mathrm{~B})[9,10,20,22-26]$. We could distinguish three types of precipitates with $\mathrm{K}$-antimonate, 1) exactly Ca-antimonate $\left.\left(\mathrm{Ca}\left[\mathrm{Sb}(\mathrm{OH})_{6}\right]_{2}\right), 2\right)$ antimonic acid bound with hydrogen $\left(\mathrm{H} \cdot\left[\mathrm{Sb}(\mathrm{OH})_{6}\right]\right)$, 3) just con- tamination, analyzed under a JEM-2010F/GIF at $200 \mathrm{KV}$ as shown in Fig. 15B-D. EELS spectra show $\mathrm{Ca} \cdot \mathrm{L}, \mathrm{O} \cdot \mathrm{K}$, $\mathrm{Sb} \cdot \mathrm{M}$ (Ca-antimonate) in 1), and a clot composed of fine needle-like crystals was observed under a high power enlaged (200,000-400,000 X) 0-loss image at $200 \mathrm{KV}$ (Fig. 15C); in 2), $\mathrm{O} \cdot \mathrm{K}$ and $\mathrm{Sb} \cdot \mathrm{M}$ EELS spectra (antimonic acid), were observed with some foamy structure as a 0-loss image, and in 3), no $\mathrm{Ca}$, O, or $\mathrm{Sb}$ spectra were observed with only irregularly shaped homogeneous electron opaque dots under 0-loss image. Most of the precipitates were Ca-antimonate, but it is very difficult to differentiate them with EDX analysis and low magnification 0-loss image.

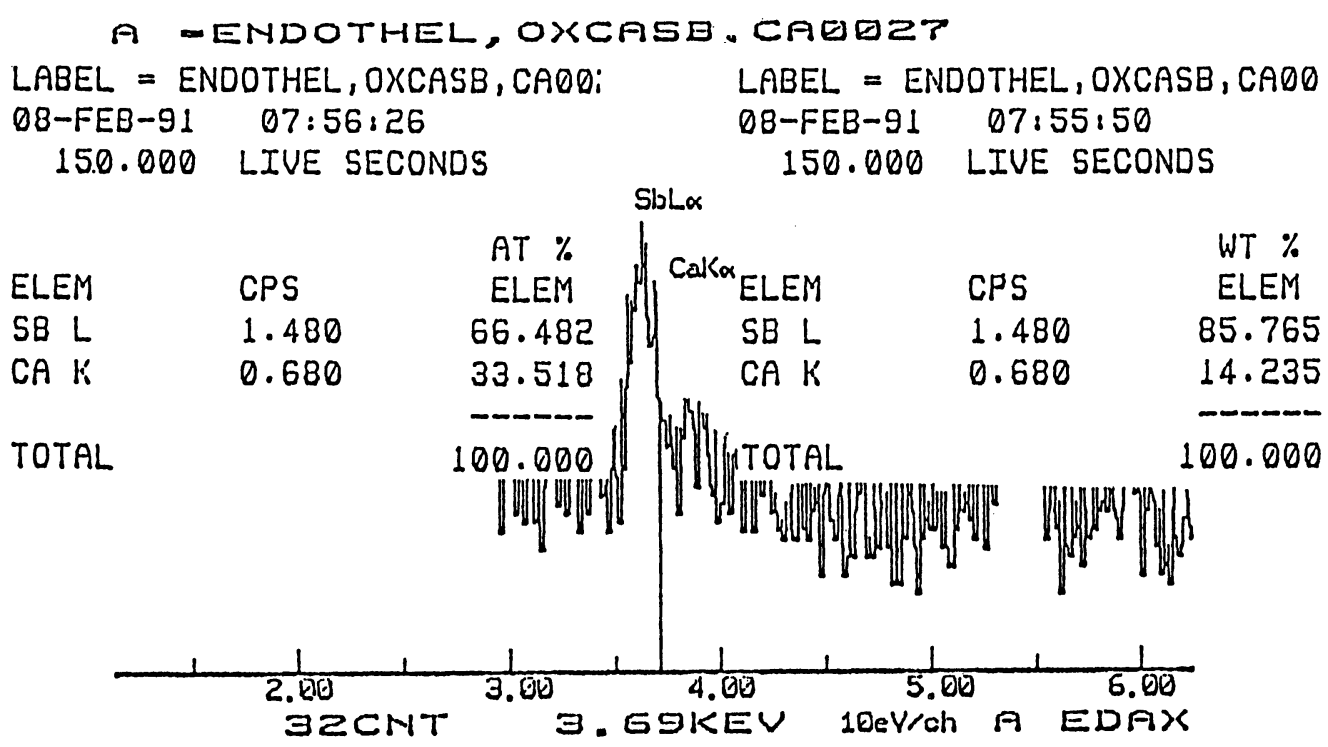

Fig. 4. EDX analyzed spectrum was obtained from the precipitates in the caveolae of the blood capillary endothelial cells in cardiac muscle. The precipitates are very fine and scarse, but the computer analyzed data were the same as those of Ca-antimonate.
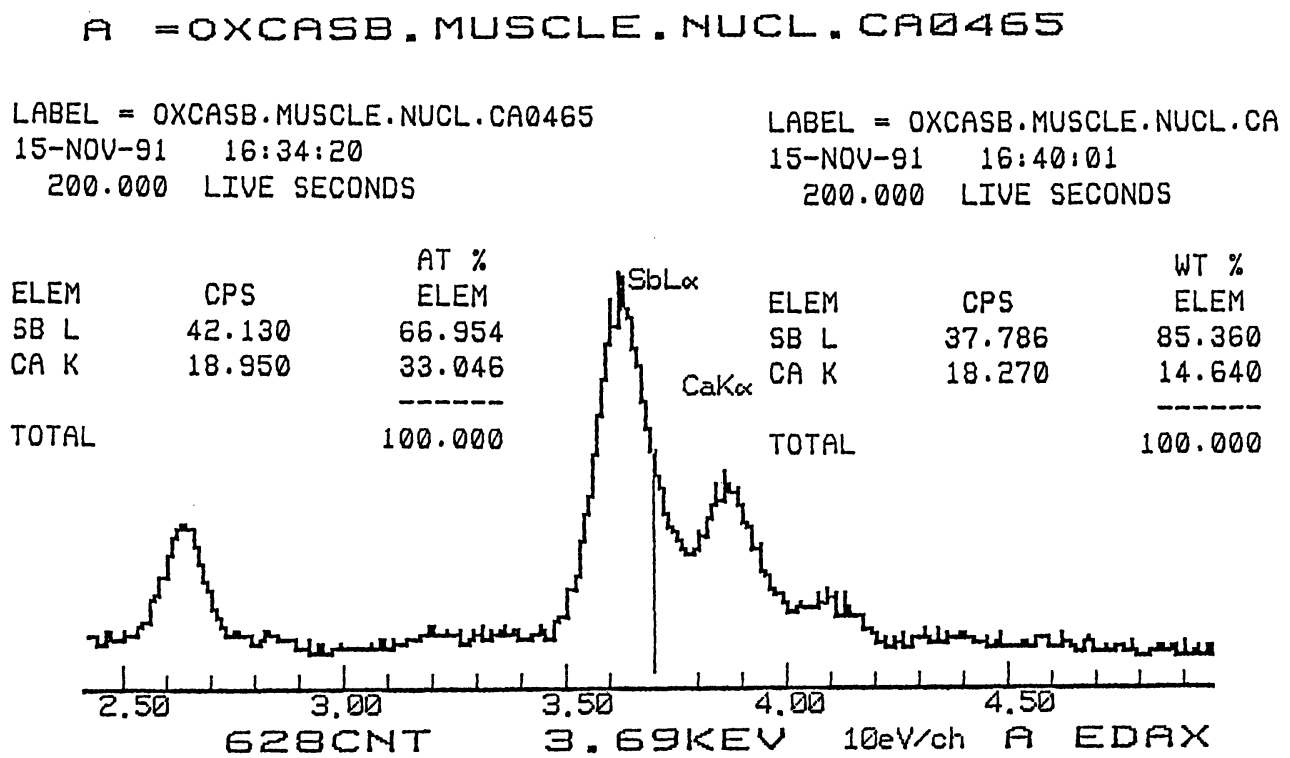

Fig. 5. EDX analyzed data was obtained form the precipitates in the cardiac muscle cell nucleus. The computerized data show the same valuesas as those of standard Ca-antimonate crystals, in normal conditions (Fig. 1). 
For photographic recording, we sometimes used Fuji Imaging Plates, (IP) instead of conventional emulsion film because the IP has very high resolution, high sensitivity, and very wide dynamic range compared to photographic emulsion film. Electron sensitized IP were analyzed with a Fuji FDL-5000 image analyzer (Fig. 16; Fiji Film Ind. Co.,Ltd., Japan).

\section{Results}

\section{Conventional Electron Microscopy with MWI Fixation and Staining}

In the rat central nervous tissues, a rapid fixation effect on living cells is present, which is comparable to rapid freezing fixation [12, 15-17, 19-26]. In Fig. 8A-C (arrows), many synaptic vesicles were seen opening at the presynaptic membranes of central nerve synaptic terminals

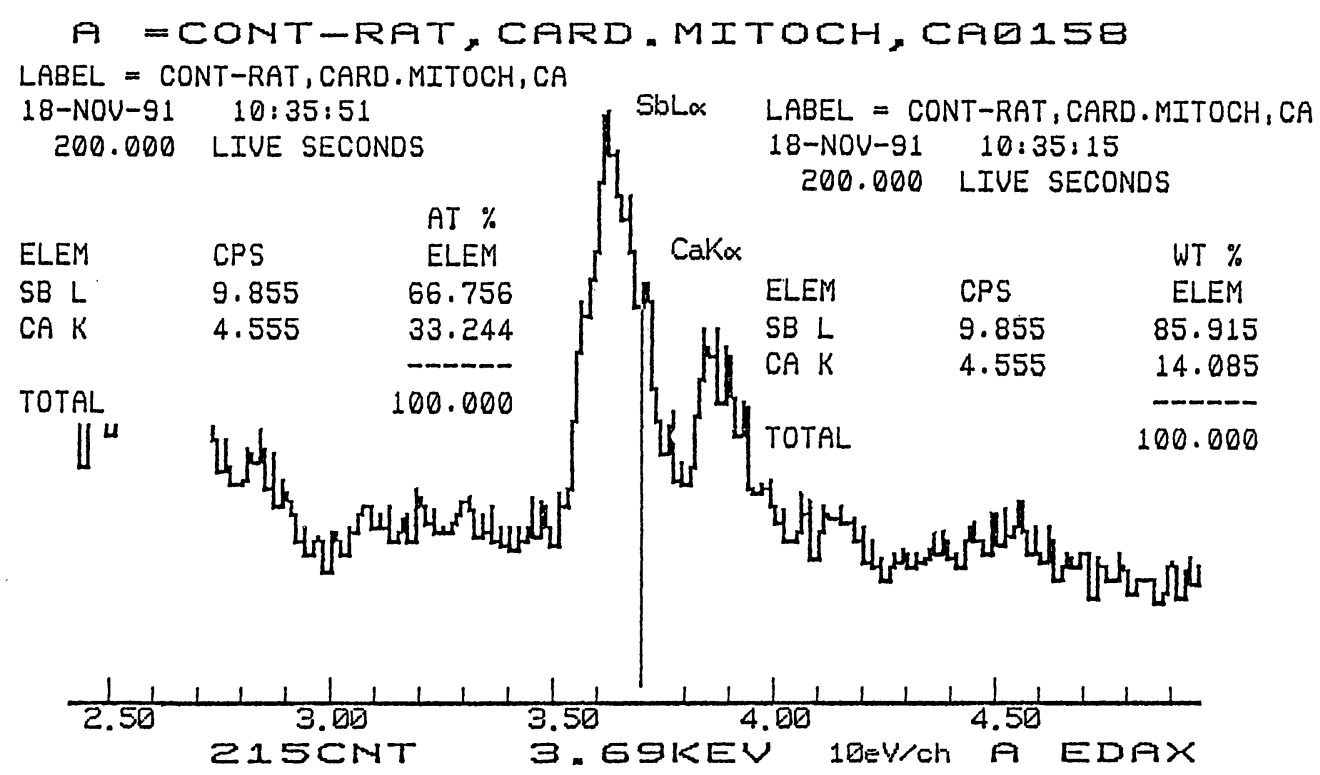

Fig. 6. An EDX analyzed spectrum was obtained from the precipitates in the cardiac muscle mitochondria. The computer calculated data are those of the standard crystals of Ca-antimonate (see, Fig. 1). In abnormal conditions, such as diabetes, calcium is depleted prominently in the muscle mitochondria [27].

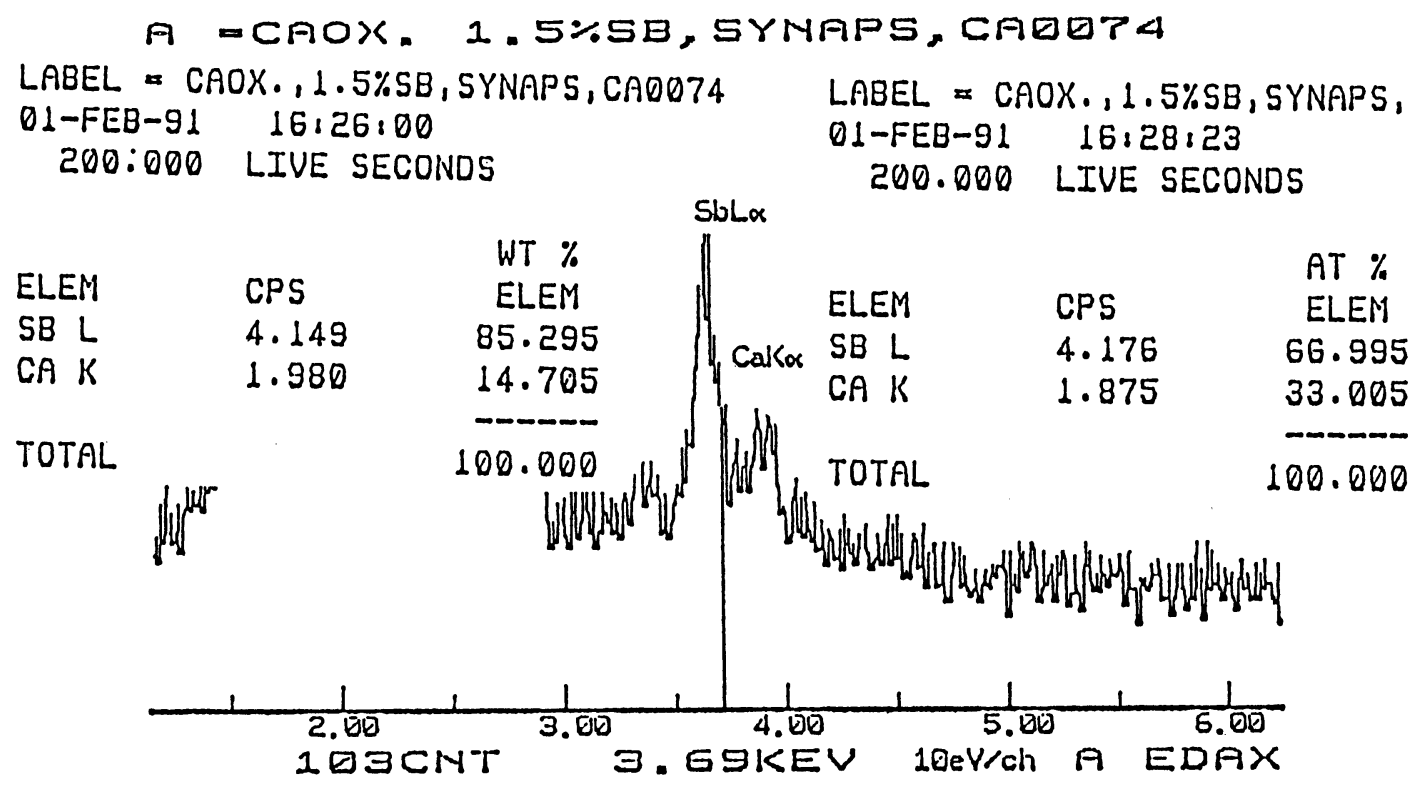

Fig. 7. An EDX analyzed spectrum was obtained from the precipitates in the rat synaptic terminal of medulla oblongata. The spectra and computer calculated values coincided exactly with those of the theoretical and standard sample analyses. Calcium actually exists in the synaptic vesicles, as shown in the data of EELS analysis (Fig. 18). 


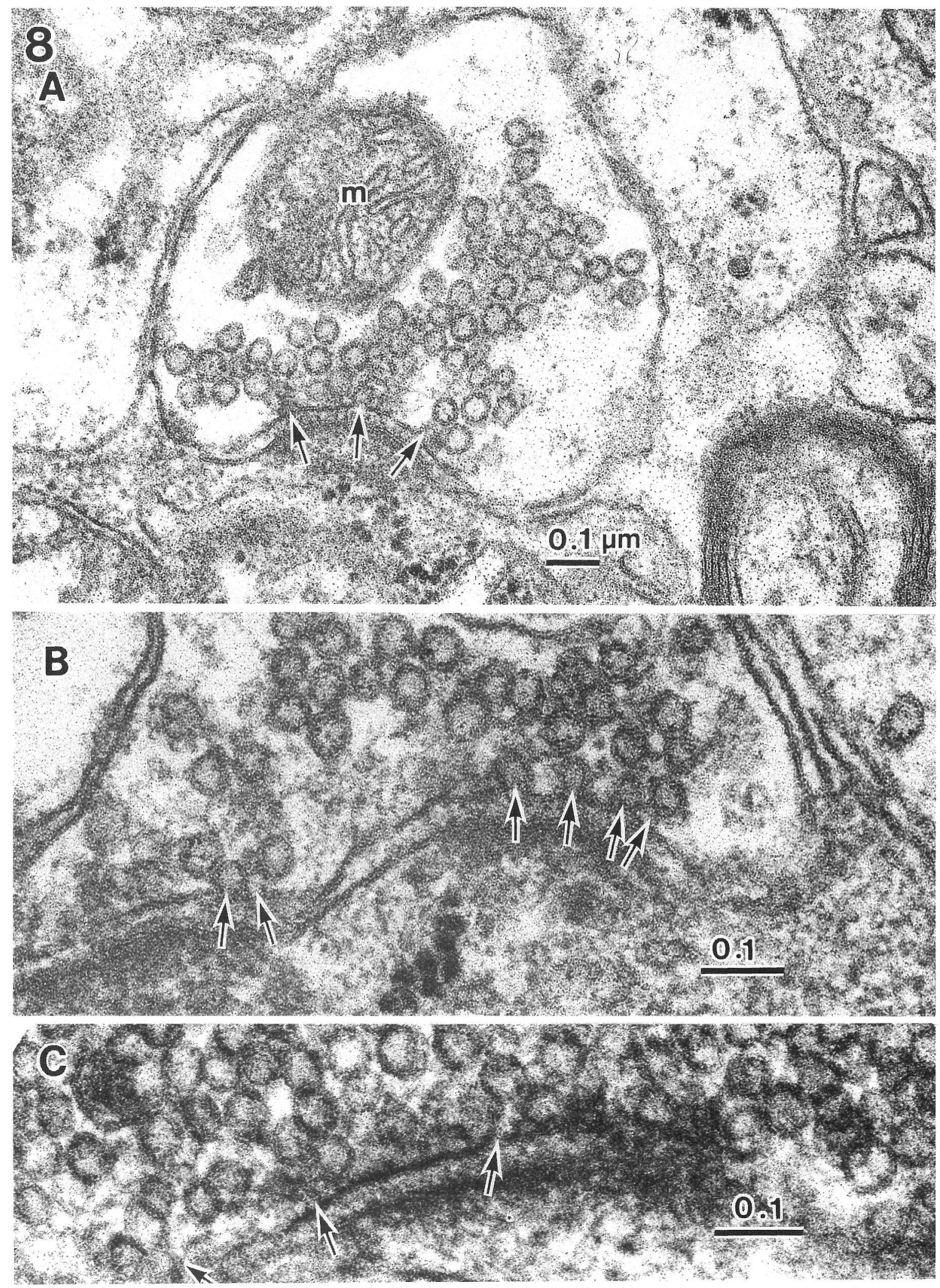

Fig. 8. A: High magnification electron micrograph of an aminergic synapse in a rat medulla oblongata. Synaptic vesicles opening at the presynaptic membrane can be seen (arrows). m: mitochondrion. MWI fixed and MWI stained. B: Synaptic vesicles opening at the presynaptic membrane in a rat medulla oblongata (arrows) can be clearly seen. MWI fixed and MWI stained. C: Cerebrum, opening synaptic vesicles and canalicular connections between the synaptic vesicles and presynaptic membrane are visible (arrows). MWI fixed and MWI stained. 


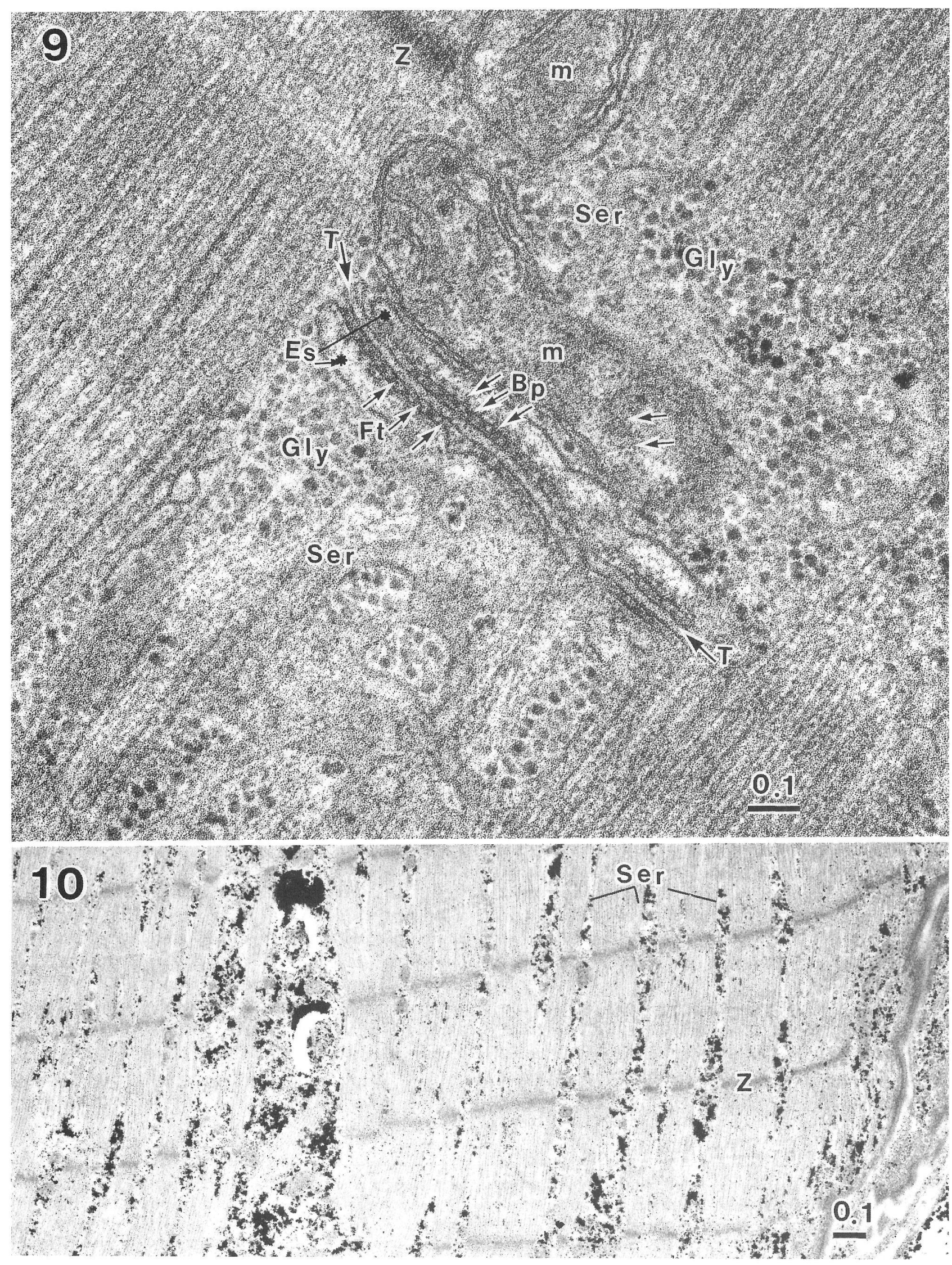

Figs. 9, 10 
of the medulla oblongata, cerebellum, and cerebrum. In some cases, there can be seen opening synaptic vesicles and canalicular connections between the vesicles and presynaptic membrane (Fig. 8C, arrows). Mitochondria, neurotubules, and myelin are also very clear. In some cases, we observed tubular connections between the mitochondrial surface membrane and neurotubules $[12,19,26]$.

In the skeletal muscle and cardiac muscle tissues, the fine ultrastructures are clearly seen: filamentous structures, myofibrils, myofilaments, Z-band (Fig. 9, Z), mitochondria with cristae and ATP-synthesize granules (Figs. 9, m; 12A-D, arrows), glycogen granules (Fig. 9, Gly), membraneous structures, sarcoplasmic membrane, transverse tubules (Fig. 9, Ser, T), and sarcoplasmic reticula with endosacs (Fig. 9, Es). Fine structures in the T-tubule/ endosac area connecting calcium binding proteins, filamentous clots arranged on the inside surface of the endosac running parallel to the T-tubules (Fig. 9, Bp) and calcium release proteins, foot processes, electron opaque spots arranged in the space between T-tubules and endosac membranes can clearly be seen (Fig. 9, Ft).

Pinocytotic vesicles or caveolae are observed along the surfaces of cardiac sarcoplasmic membranes and endothelial cells of blood capillaries associated with their basement membranes (Fig. 13C).

Such rapid fixation images and extremely fine structures with high electron opacity are only seen after MWI fixation using a fixative containing tannic acid and electron staining with MWI, as shown for various other tissues as well $[12,15-19,21,24-26]$.

\section{Calcium Ion Detection with EDX Analysis}

Standard samples of Ca-antimonate crystals were obtained after Ca-oxalate was substituted with $\mathrm{K}$-antimonate solution in a glass tube for $24 \mathrm{hr}$. Substituted crystals were rinsed with distilled water several times and dried. Substituted powder crystals were analyzed by computerized EDX. The data showed a typical X-ray spectrum of Ca-antimonate (Fig. 1), in which Ca-oxalate was replaced completely by Ca-antimonate. Computer calculated values of the characteristic X-ray pulse counts of $\mathrm{Ca} \cdot \mathrm{K}$ and $\mathrm{Sb} \cdot \mathrm{L}$ of $\mathrm{AT}$ and WT (\%) coincided with the theoretical values for Ca-antimonate (see, Introduction) $[12,19,21,26]$.

Using the 2-step Ca-ion detection method, i.e., the $\mathrm{K}$-oxalate/K-antimonate substitution method, electronopaque fine precipitates of $\mathrm{Ca}$-antimonate were detected in the skeletal muscle, sarcoplasmic reticula, endosacs, mito- chondria, and nucleus (Fig. 10). Fig. 11 shows a high magnification of a part of the skeletal muscle, centered on the sarcoplasmic reticula and endosacs, and transverse tubules area. A large amount of precipitates accumulated in the Ser and endosacs (Es), and some in the mitochondria and nucleus (the nucleus is not shown in this figure), but not in the T-tubules (Fig. 11). In cardiac muscle, precipitates were seen in the Ser, mitochondria, and nucleus, along the membrane surface of the intercalated disks (Fig. 13A, B), and in caveolae in the surface of the sarcoplasmic membrane of the cardiac muscle and the endothelial cells (Fig. 13C).

In central nerve terminals, fine Ca-antimonate precipitates were observed in the synaptic vesicles, mitochondria, and synaptic membranes with their ultrastructures preserved (Fig. 14A-D). As mentioned in the Introduction, best results can be obtained by keeping the density of K-oxalate low (30-40 mM for nervous tissue, and 40-60 $\mathrm{mM}$ for other tissues) and $\mathrm{K}$-antimonate (1$1.5 \%$ ) in the fixative (see and compare, Figs. 10, 11, 12C, 13A-C, 14A-D). In Fig. 14A and B, in which we used $60 \mathrm{mM}$ of oxalate in the fixative, a large amount of precipitates filled up the synaptic vesicles, and some structual deformation or destruction could be seen caused by the grown precipitates. However, in Fig. $14 \mathrm{C}$ and D, we used less, $30 \mathrm{mM}$ of oxalate and $1 \%$ of $\mathrm{K}$-antimonate, and very fine precipitates appeared in the synaptic vesicles, mitochondria, and synaptic membranes, and the ultrastructures were preserved well by the MWI fixation.

EDX data from the skeletal and cardiac muscle tissues, in the Ser, endosacs, mitochondria, and nucleus, are shown in Figs. 2-6. Computer calculated values indicate Ca-antimonate, as shown in these figures, in both AT and WT (\%) values (Figs. 1-6). In the synaptic terminal, precipitates in the synaptic vesicles, synaptic membranes, and mitochondria were also complately the same as those of the standard sample of Ca-antimonate (Figs. 1 and 7). The data showed the existance of calcium ions.

In the control study, where the section was floated on a solution of EDTA or EGTA at $60^{\circ} \mathrm{C}$ for $60 \mathrm{~min}$, Caantimonate precipitates dissolved and disappeared from the section, and no $\mathrm{Ca} \cdot \mathrm{K} \alpha$ and $\mathrm{Sb} \cdot \mathrm{L} \alpha$ were detected by EDX analysis, as in previous experiments [12, 21].

It is impossible to demonstrate calcium distribution directly as an elemental characteristic X-ray pulse image, because the intensity of the X-ray pulses is so low.

Fig. 9. Rat intercostal muscle fiber, MWI fixed and MWI stained. Ultrafine structures are very clear. Bp: calcium binding proteins; Es: endosac of sarcoplasmic reticulum; Ft: calcium releasing foot processes; Gly: glycogen granules; m: mitochondrion with fine ATP-synthesize granules or elemental particles; Ser: sarcoplasmic reticulum; T: transverse tubule; Z: Z-band.

Fig. 10. Low magnification micrograph of rat intercostal muscle, fixed with the 2-step chemical Ca-ion fixation method. A large amount of precipitates appear in the sarcoplasmic reticula (Ser). EDX analyzed data indicates calcium antimonate (Fig. 2). Calcium exists in the ionic state; $60 \mathrm{mM}$ K-oxalate was used. 


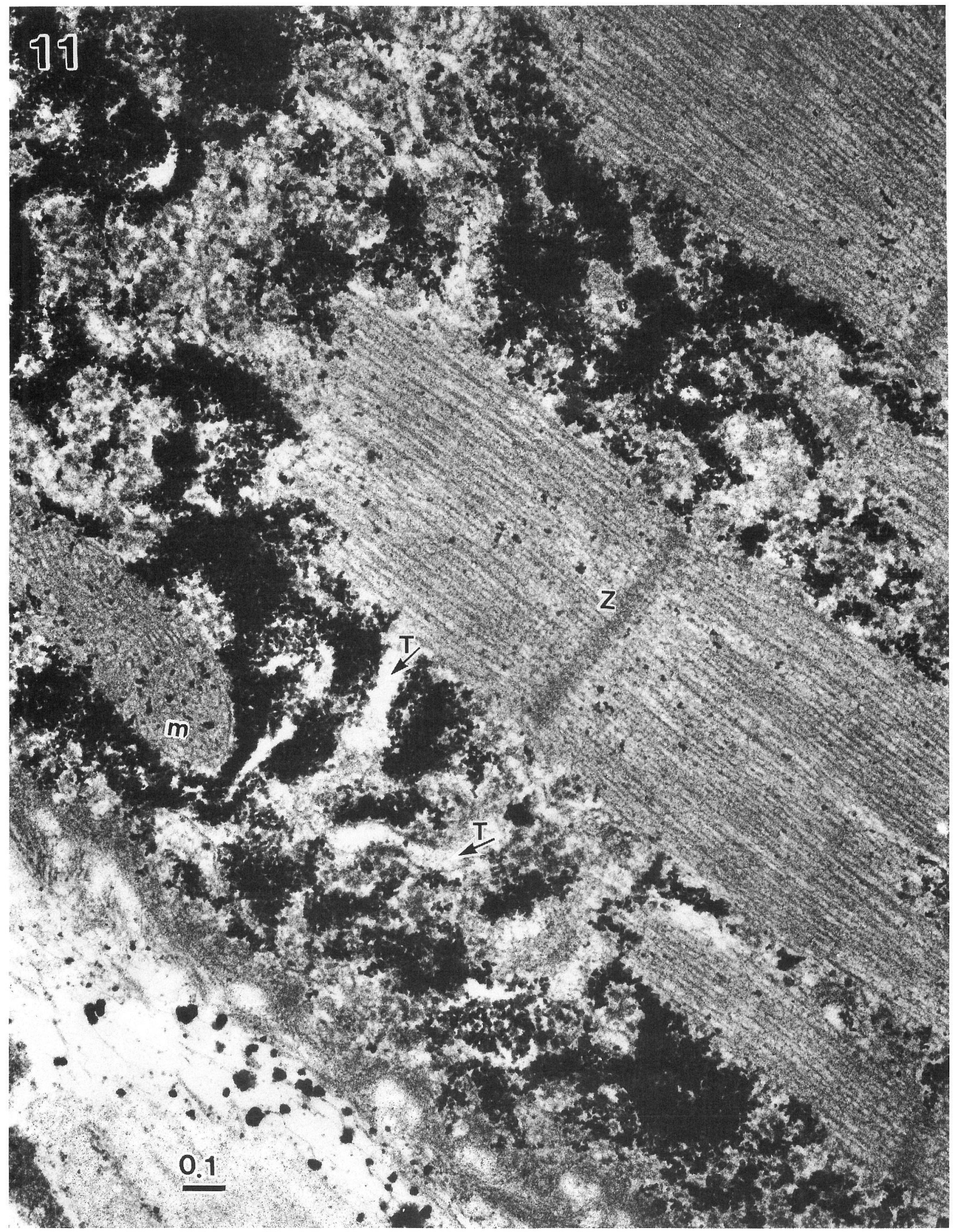

Fig. 11. High magnification electron micrograph of the resting site of intercostal muscle fiber, fixed with the 2-step Ca-ion detection method. A large amount of calcium ions was accumulated in the sarcoplasmic endosac, $60 \mathrm{mM} \mathrm{K}$-oxalate was used. m: mitochondrion; T: transverse tubules; Z: Z-band. Analyzed EDX data are shown in Fig. 2. 


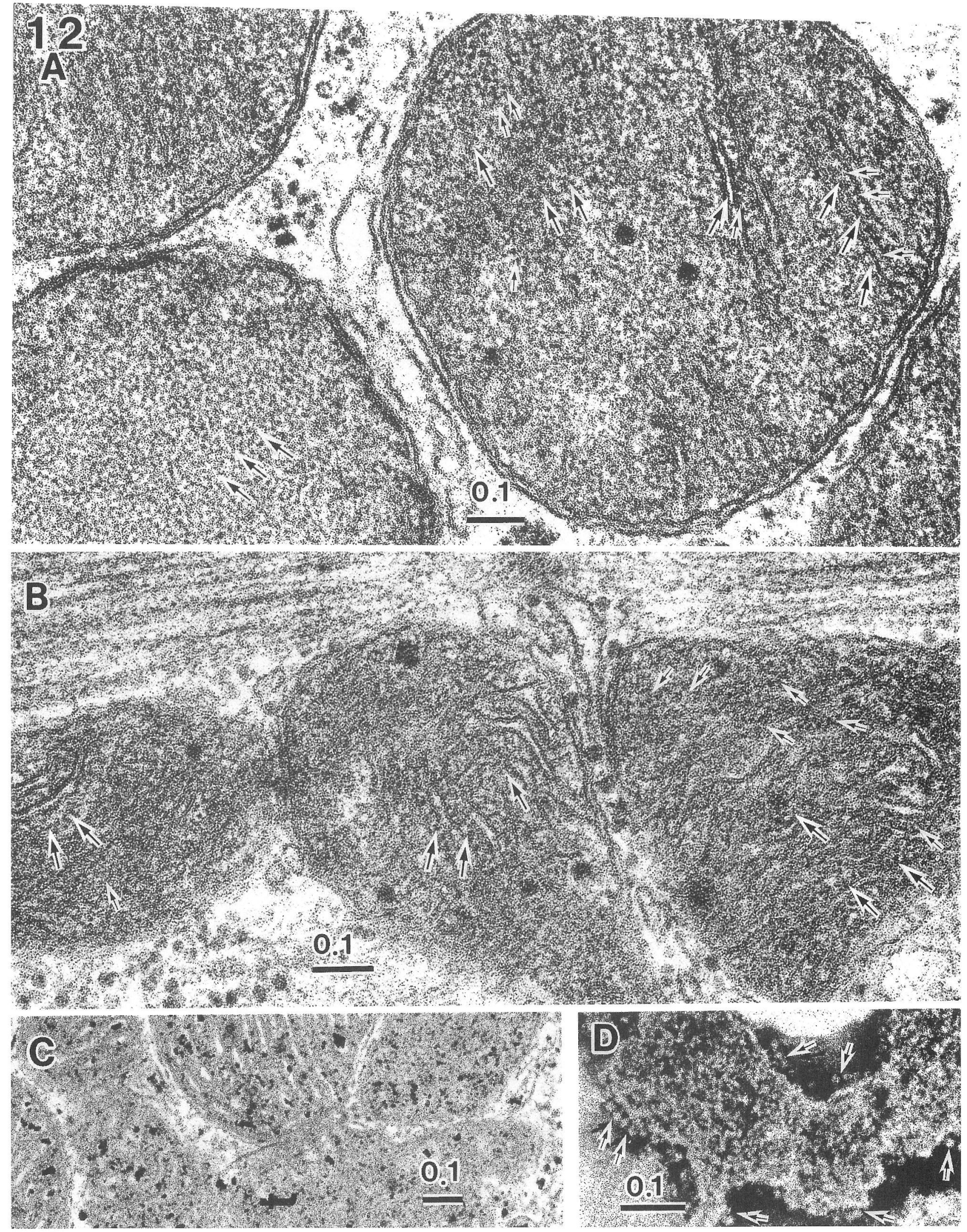

Fig. 12. MWI fixed and MWI stained mitochondria. A: is kidney, and $\mathbf{B}$ : is cardiac muscle. Very fine granular structures are observed in the mitochondria (arrows) arranged on the membranes of the cristae. They are ATP-synthesize or elemental particles as shown in the negatively stained fresh mitochondrion (D, arrows). Ca-antimonate precipitates appared in the mitochondria; $40 \mathrm{mM}$ K-oxalate was used (C, Fig. 6). 

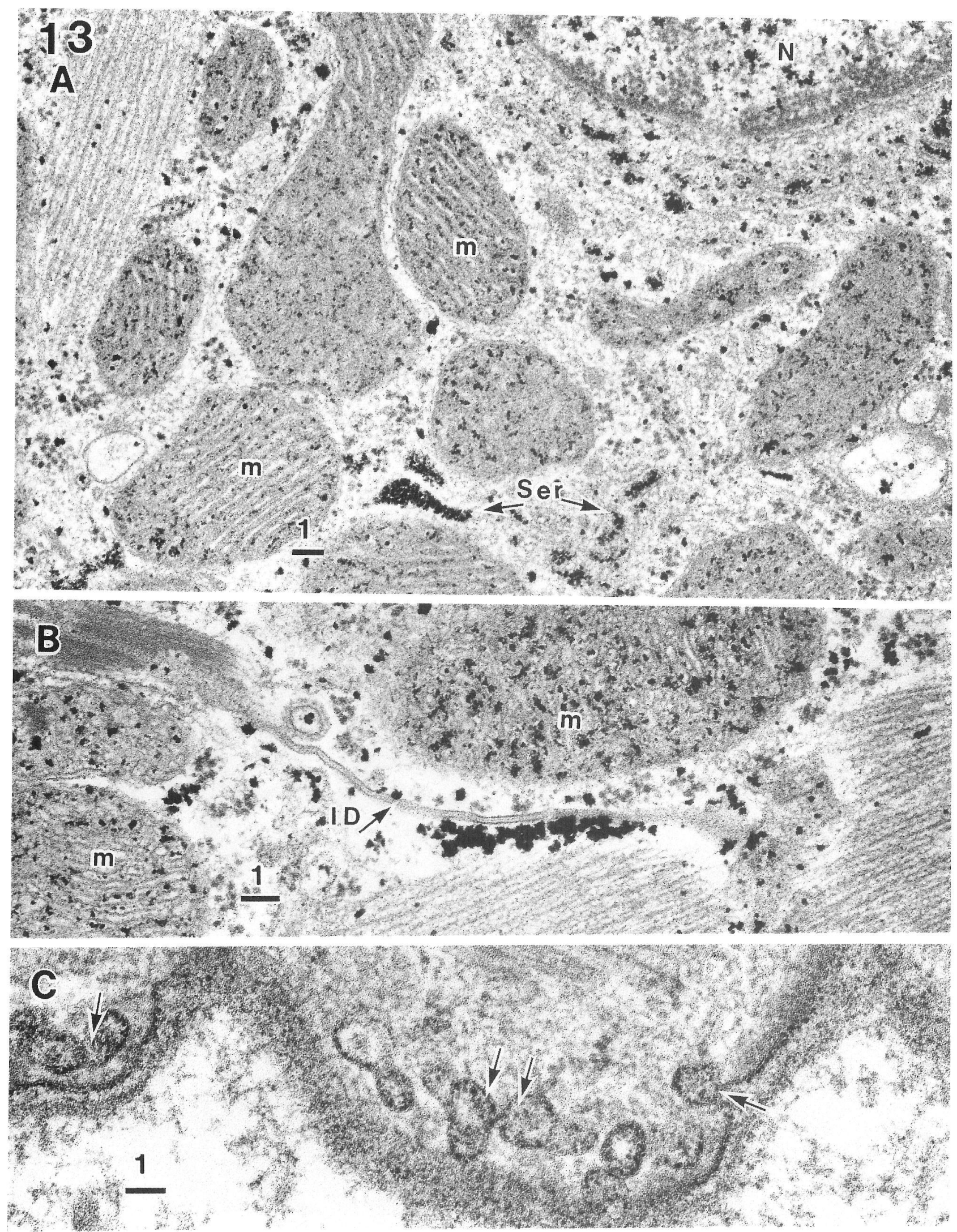

Fig. 13. 2-step chemical fixation under MWI, cardiac muscle. A: Ca-antimonate precipitates are distributed in mitochondria (m), sarcoplasmic reticulum (Fig. 3; Ser), and nucleus (N) (Figs. 3-6). B: Ca-antimonate precipitates are seen beneath one side of the intercalated disc (ID) and mitochondria (Fig. 6; B). C: is a part of an endothelial cell of a blood capillary in the cardiac tissue, fixed with 2-step chemical method using $30 \mathrm{mM} \mathrm{K}$-oxalate and 1.5\% K-antimonate for the detection of calcium ion. Calcium actually exists in the caveolar cavities (arrows; Fig. 4). 


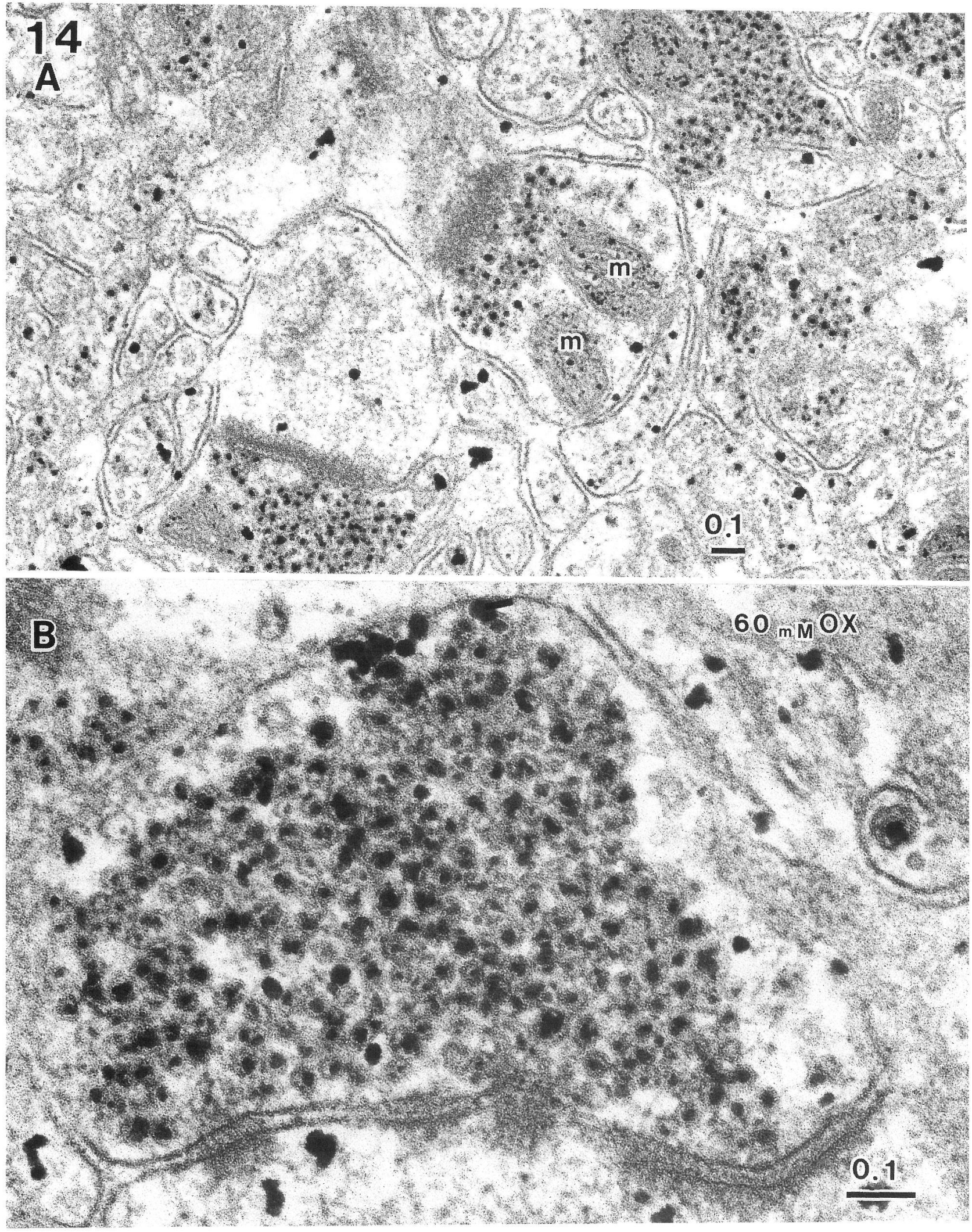

Fig. 14A, B. Rat brain, K-oxalate/K-antimonate 2-step method of $\mathrm{Ca}^{2+}$ ion detection, when $40 \mathrm{mM} \mathrm{K}$-oxalate was used. Precipitates are distributed in the synaptic vesicles and mitochondria. However, precipitates have grown large, and occupy the full space of the synaptic vesicles. If $60-90 \mathrm{mM} \mathrm{K}$-oxalate is used, precipitates grow further, and membraneous ultrastructures are broken. A: low magnification $(60,000 \times)$; B: high magnification $(120,000 \times)$. 
Calcium Ion Distribution detected by EELS-Imaging Analysis

A typical EELS spectrum of Ca-antimonate was obtained from the standard sample as well as precipitates in a section. Ultrathin sections of skeletal and cardiac muscles and central nerve tissues were obtained from the same tissue blocks as those used for the EDX analysis, although they were cut thinner, at $30 \mathrm{~nm}$. The sections were analyzed without carbon coating or electron staining, mounted on 400 /grid mesh.

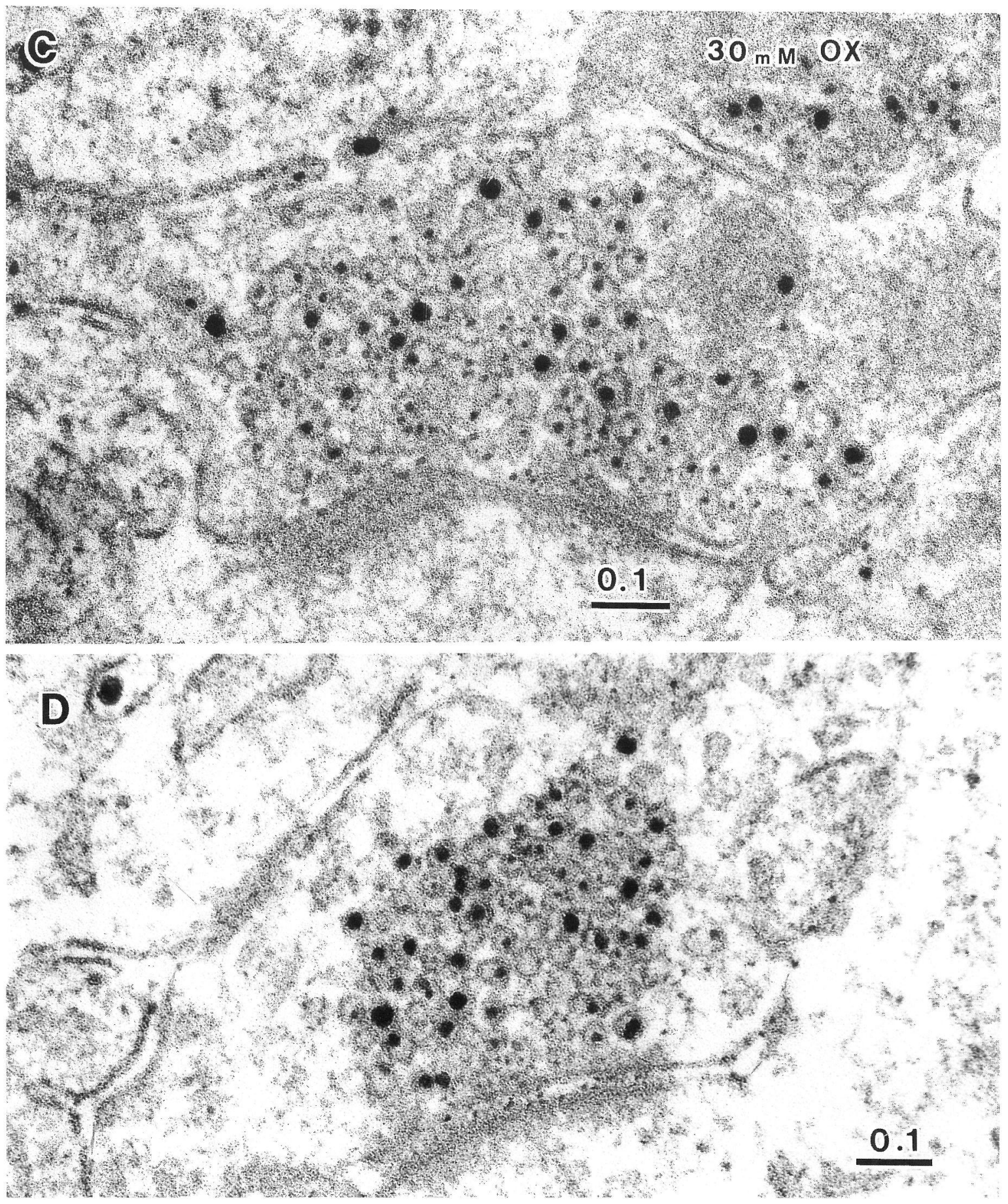

Fig. 14C, D. $30 \mathrm{mM}$ K-oxalate was used. Very fine precipitates are seen inside of the synaptic vesicles and mitochondria, or along the synaptic membranes (arrows). The concentration of K-antimonate for substitution seems important. Lower concentrations (1-1.5\%) produce excellent results, when compared to the normal concentration of $2.0 \%$. EDX analyzed data indicate that precipitates are Ca-antimonate itself, and computer calculated values of AT (\%), and WT (\%), coincide with those of the theoretical values (see, Figs. 1, 7). 

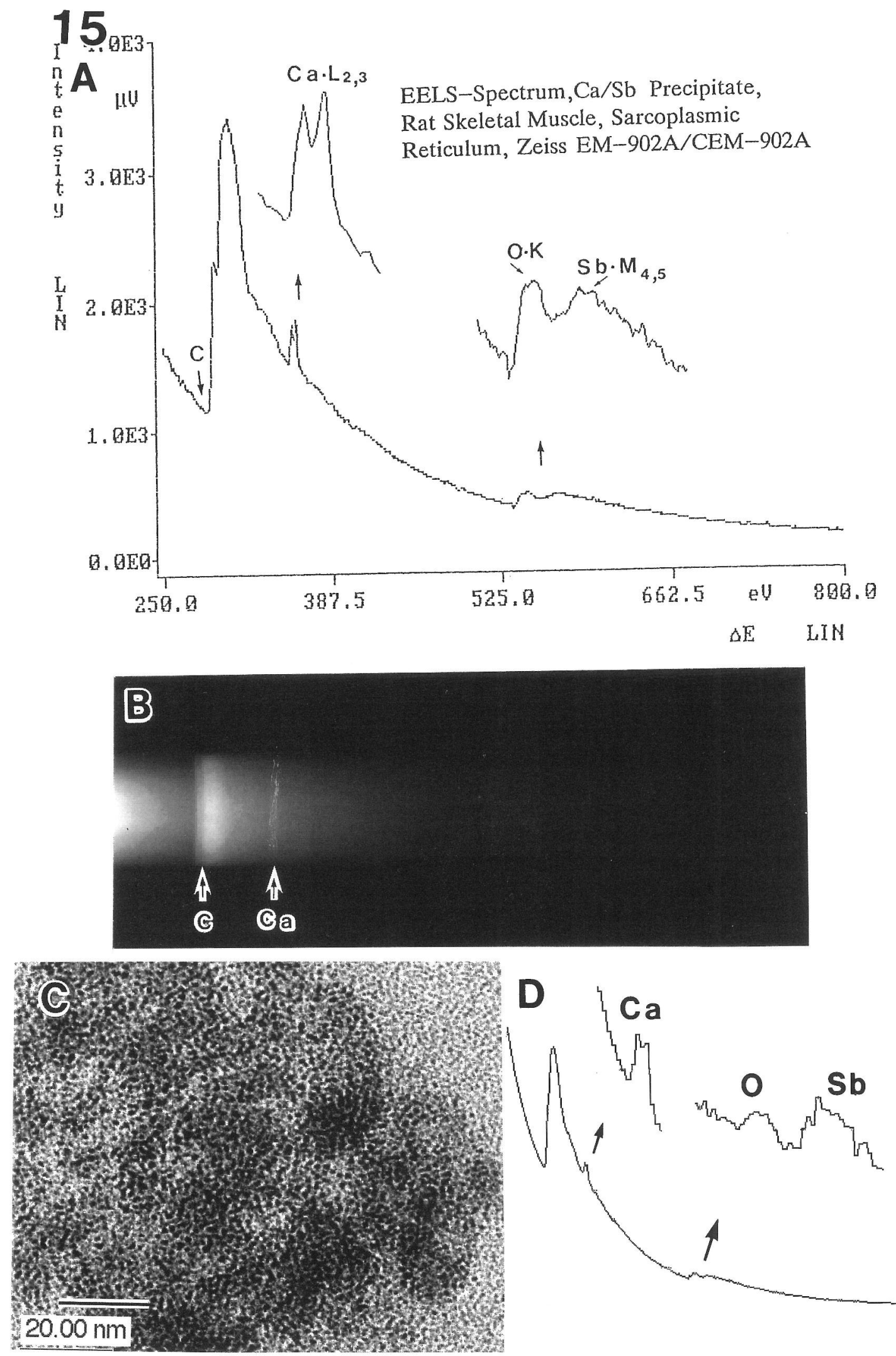

Fig. 15. A: EELS spectrum was analyzed from the precipitates of Ca-antimonate in the endosac of the skeletal muscle. C.K (303 eV), Ca.L $(355 \mathrm{eV}), \mathrm{O} \cdot \mathrm{K}(544 \mathrm{eV})$ and $\mathrm{Sb} \cdot \mathrm{M}(590 \mathrm{eV})$ were obtained clearly. Zess EM-902A/CEM-902A, at $80 \mathrm{KV}$; B-D: JEM-2010F/GIF analyzed EELS data at $200 \mathrm{KV}$. B: EELS-spectrum analyzed Ca-antimonate precipitate in the endosac of rat skeletal muscle. C.K and Ca.L absorption bands are clear. C: 0-loss image of a precipitate in the section, $200.000 \times$. D: Density spectrum obtained from B. C.K, Ca. L, O.K, and $\mathrm{Sb} \cdot \mathrm{M}$ energy absorption peaks are clear. 

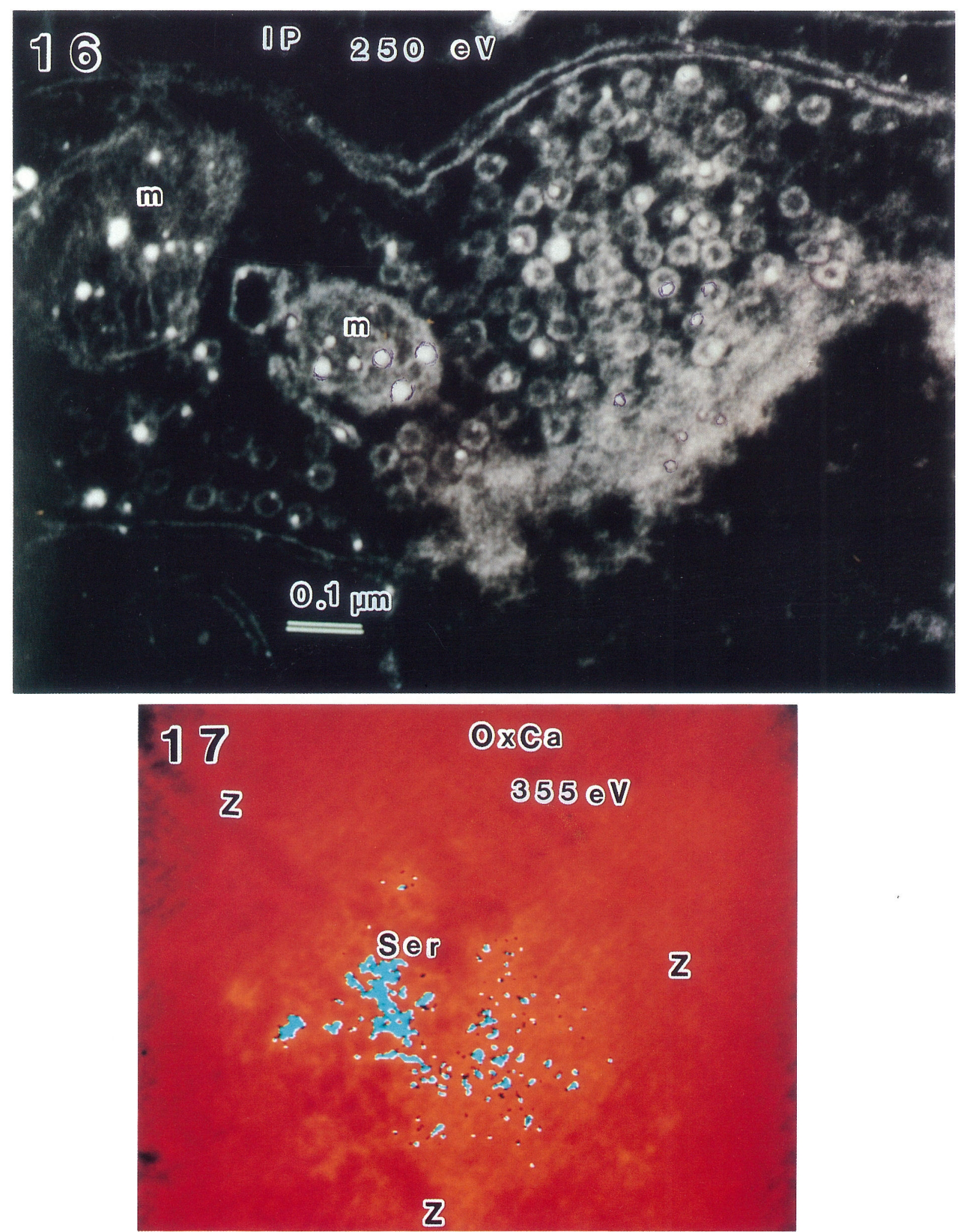

Fig. 16. Electron energy filtered spectroscopic image (dark field-like image) of a rat brain synapse at 250 eV. A Fuji Imaging plate (IP) was used instead of photographic silver halide emulsion film to take the electron micrograph (Zeiss EM-902A/Fuji-IP/Fuji-FDL 5000).

Fig. 17. Net Ca.L EELS image at $355 \mathrm{eV}$ after background image was subtracted. Rat intercostal muscle, $40 \mathrm{mM} \mathrm{K}$-oxalate containing aldehyde fixative with MWI, embedded in Epon without K-antimonate substitution or postfixation. Precipitate of Ca-oxalate is located in the sarcoplasmic reticutum (Ser), as shown in blue color dots, superimposed on a dark field-like image at $250 \mathrm{eV}$ (red color). Z: Z-band of myofibril. (Zeiss EM-902A/IBAS). 

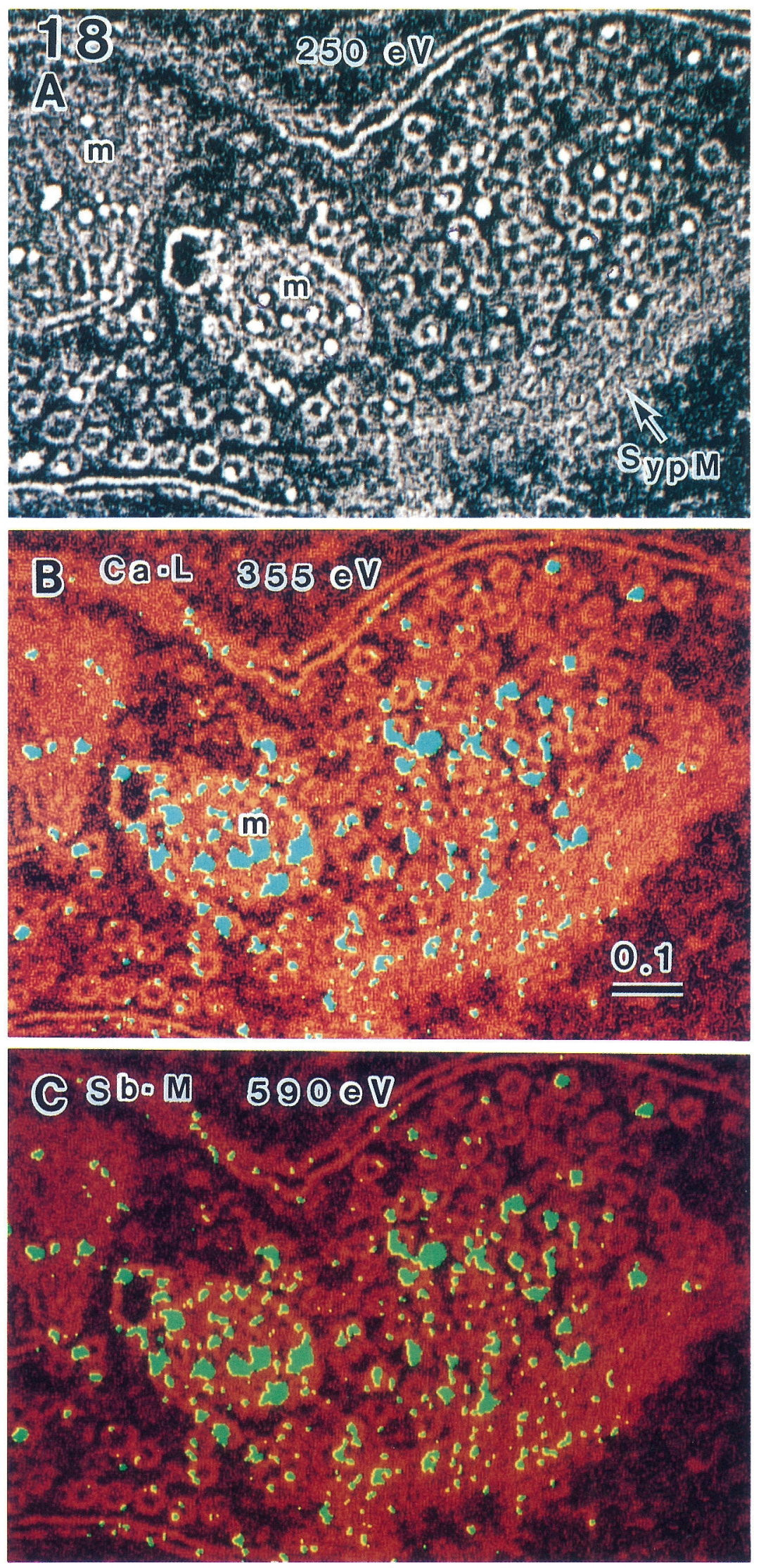

Fig. 18 
Fig. 15A-D shows the $\mathrm{Ca} \cdot \mathrm{L}_{2,3}$ (maximum peak value, $355 \mathrm{eV}), \mathrm{O} \cdot \mathrm{K}(544 \mathrm{eV})$ and $\mathrm{Sb} \cdot \mathrm{M}_{4,5}(590 \mathrm{eV})$ EELS spectra obtained from the precipitates in a skeletal muscle section. The same data were obtained from the other, cardiac muscle and nerve terminal sections, as well.

Fig. 17 shows the Ca.L EELS image (blue dots) of rat skeletal muscle superimposed on the dark field-like image at $250 \mathrm{eV}$ (electron energy filtered spectroscopic image, red color). The specimen was fixed with K-oxalate containing fixative under MWI and embedded in Epon without replacement with $\mathrm{K}$-antimonate. Ultrastructual images are not good, but Z-bands and myofibrils can be differentiated. Localization of calcium is not sharply demarcated and there is less than in the 2-step replaced sections, as shown in the following Figs. 19B and 20A, B. Part of the Ca-oxalate precipitate in the section was leached out during the embedding procedure, because $\mathrm{Ca}$ oxalate is partly soluble in water.

Fig. 19 shows rat intercostal muscle fixed with the 2step chemical fixation method under MWI, analyzed with a JEM-2010F/GIF at $200 \mathrm{KV}$. A is a 0-loss image, showing electron opaque $\mathrm{Ca}$-antimonate precipitates condensed in the sarcoplasmic reticula and endosacs holding the $\mathrm{T}$-tubules between them. B shows the net $\mathrm{Ca} \cdot \mathrm{L}$ image (blue color), $\mathrm{C}$ is the $\mathrm{Sb} \cdot \mathrm{M}$ image (green), and $\mathrm{D}$ shows the $\mathrm{O} \cdot \mathrm{K}$ image (eyellow), after the background images were subtracted. The data show that the precipitate is Ca-antimonate (Fig. 15B-D). In this series, from B to D, their dark field-like spectroscopic images were not superimposed on their net elemental images (compare to Fig. 20B, C).

Figure 20A shows a net Ca.L EELS image of the sarcoplasmic reticula and endosacs holding $\mathrm{T}$-tubules between them in the interfibullar space of rat intercostal muscle, after the background image was subtracted at $355 \mathrm{eV}$. Fig. 20B shows the net $\mathrm{Ca} \cdot \mathrm{L}$ image (light blue) superimposed on the energy filtered dark field-like image (red color background) at $250 \mathrm{eV}$. Fig. $20 \mathrm{C}$ is the net $\mathrm{Sb} \cdot \mathrm{M}$ EELS image at $590 \mathrm{eV}$ (light green) superimposed on the dark field-like image (red color background). These serial EELS images show that calcium is located in the sarcoplasmic reticula and endosacs in the resting skeletal muscle fiber in an ionic state.

In cardiac muscle, almost the same distribution was observed. Calcium was also localized in the sarcoplasmic reticula, nucleus, and mitochondria, as shown in Fig. 21.

In the central nerve terminals, synaptic vesicles, synaptic membranes, and mitochondria, typical EELS spectra of Ca-antimonate were obtained. Fig. 16 shows an exam- ple of a spectroscopic dark field-like image of a synaptic terminal obtained with a Fuji imaging plate (IP) at $250 \mathrm{eV}$, instead of the photographic emulsion film. The digital EELS image was obtained with a Fuji FDL-5000 image analyzer. Fine details are very clear, even in very thin, unstained sections, compared to Fig. 18A (arrows). The same image was stored on a disk as a digital image, then analyzed with a Zeiss IBAS image analyzer, as shown in Fig. 18A. Thus net Ca.L (light blue) and $\mathrm{Sb} \cdot \mathrm{M}$ (light green) EELS images were superimposed on the dark fieldlike images (red) as shown in Fig. 18B and C. Calcium is distributed in the synaptic vesicles, synaptic membranes, and mitochondria. Antimony ( $\mathrm{Sb}$ ) is distributed in the same sites as calcium.

Most of the precipitates in the cell were $\mathrm{Ca}$ antimonate, but some of them were not Ca-antimonate, but antimonic acid or just contamination, as seen under high magnification $(200,000-400,000 \mathrm{X})$ in 0-loss images using JEM-2010F/GIF at $200 \mathrm{KV}$. Ca-antimonate precipitate shows a clot of fine needle-like crystals and typical EELS spectra of Ca-antimonate (Fig. 15C), antimonic acid shows a foamy electron opaque spot with $\mathrm{Sb} \cdot \mathrm{M}$ and $\mathrm{O} \cdot \mathrm{K}$ EELS spectra, and contamination show only irregularly shaped electron opaque homogeneous spots without spectra.

\section{Discussion}

We have previously described the MWI fixation method for biological specimens in detail, including fixative solutions containing tannic acid, use of a microwave oven at room temperature for only 20-35 sec with unexpectedly good results, and staining with MWI. This unique fixation method produces rapid fixation with the same results as rapidly frozen sections $[12,15-19,24-26]$. Using ${ }^{3} \mathrm{H}$-formalin as a tracer, we clarified why MWI enabled the aldehyde to penetrate into the tissue block so quickly and homogeneously, and by the aid of X-ray microprobe analysis, we found why MWI enabled the staining materials to penetrate into the sections so quickly and homogeneously $[12,15,17-19,24-26]$.

There are several detecting methods for $\mathrm{Ca}^{2+}$ ion distribution in tissue and cells, as discussed previously [12, 21, 25]. The ideal method may be analysis with EDX, especially EELS-imaging in fresh frozen or freezesubstituted ultrathin sections $[9,10,12,21-26]$. However, there are still some technical drawbacks in the frozen techniques for ultrathin sections. On the other hand, several inorganic chemical precipitation methods to

Fig. 18. A: Electron energy filtered spectroscopic image (dark field-like image) of a rat brain synaptic terminal at $250 \mathrm{eV}$. Synaptic vesicles with small bright dots, mitochondria (m), and synaptic membranes (SypM) can be clearly seen. (compare to Fig. 16, IP-image). B: Net EELS image of $\mathrm{Ca} \cdot \mathrm{L}$ at $335 \mathrm{eV}$ (light blue), superimposed on a dark field-image (red color coaded background). Calcium is distributed in the synaptic vesicles, mitochondria, and presynaptic membrane. C: Net Sb $\cdot \mathrm{M}$ EELS image at $590 \mathrm{eV}$ (light green) superimposed on the dark field-like image (red). Zeiss EM-902A/IBAS. 

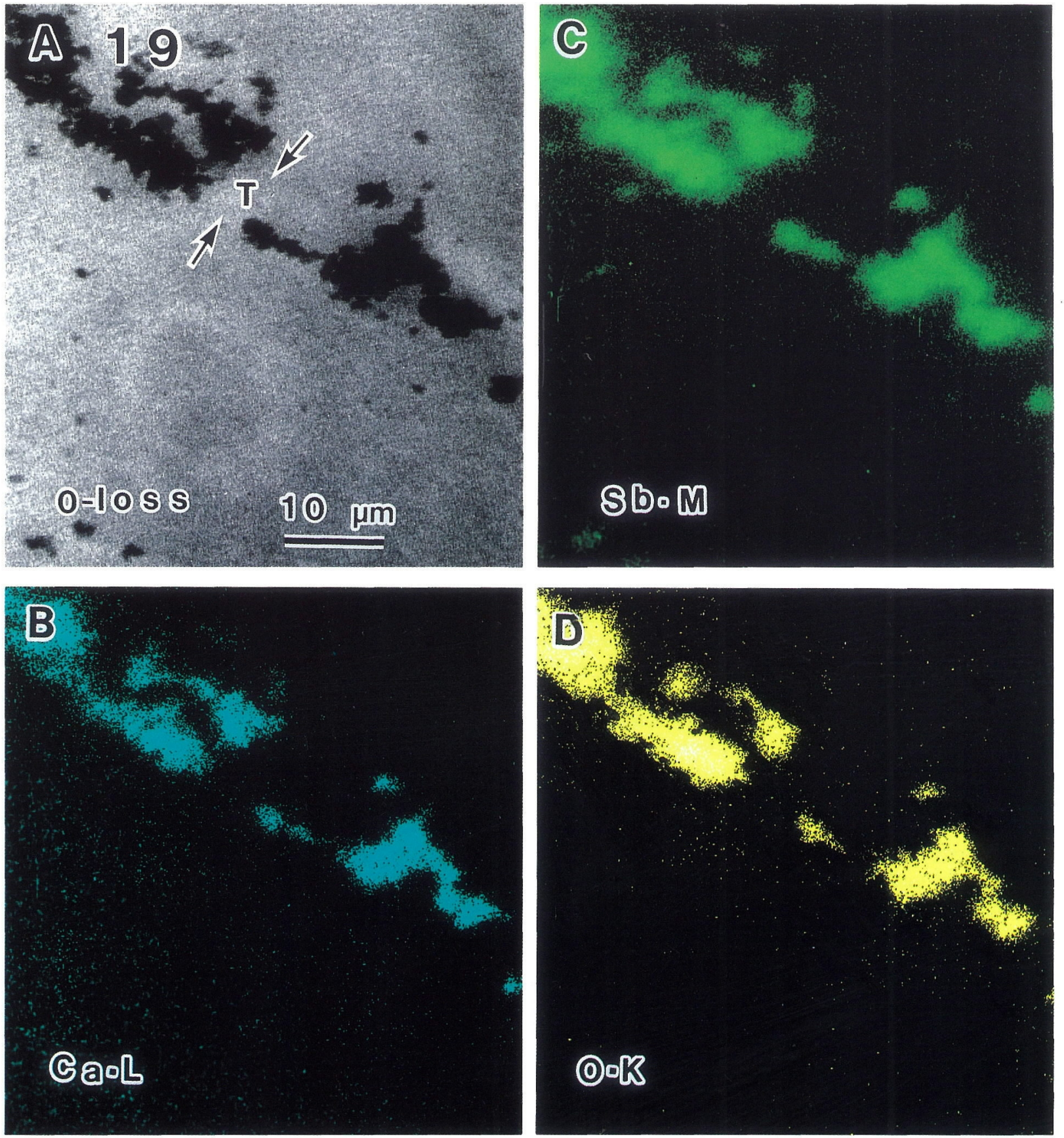

Fig. 19. Rat intercostal muscle, fixed with 2-step chemical precipitation method and MWI, analyzed with JEM-2010F/GIF at 200 KV. A: 0loss image of a part of muscle fiber; arrows and $\mathrm{T}$ indicate transverse tubule. Both sides of T-tubule are endosacs and sarcoplasmic reticula storing calcium ions appearing as Ca-antimonate precipitates. B: A net Ca.L EELS image (blue). C: A net Sb·M EELS image (green). D: A net $\mathrm{O}$.K EELS image with yellow color. These four images are from exactly the same sites; the precipitates are $\mathrm{Ca}$-antimonate, $\mathrm{Ca}\left[\mathrm{Sb}(\mathrm{OH})_{6}\right]_{2}$.

detect $\mathrm{Ca}^{2+}$ ions in tissue and cells have been tried since Komnick used K-antimonate in 1962 [see, 12, 21]. First, Komnick used $\mathrm{K}$-antimonate for the detection of $\mathrm{Na}^{+}$ions in the cell. Legato and Langer used the same chemicals to detect $\mathrm{Ca}^{2+}$ ions in 1969 [see, 12, 21]. Since then many investigators have addressed major issues concerning the chemical affinity of $\mathrm{K}$-antimonate for $\mathrm{Ca}^{2+}$ ions. Kantimonate forms precipitates with several cations, such as $\mathrm{H}^{+}, \mathrm{Na}^{+}, \mathrm{Mg}^{2+}, \mathrm{Ca}^{2+}, \mathrm{Fe}^{3+}, \mathrm{Bi}^{3+}, \mathrm{Pb}^{2+}, \mathrm{Zn}^{2+}$, and also with some proteins $[12,21,25]$. Mizuhira et al. confirmed the binding affinity of $\mathrm{K}$-antimonate for the cations, which was $\mathrm{Ca}^{2+}>\mathrm{Mg}^{2+}>\mathrm{Na}^{+}[12,21,25]$. They found that 
the sensitivity of $\mathrm{K}$-antimonate and $\mathrm{K}$-oxalate to $\mathrm{Ca}^{2+}$ ions was almost the same and that they were very sensitive at the $\mu \mathrm{M}$ level $[12,21,25]$. However, there was still a possibility that the precipitates were composed of several kinds of cations when K-antimonate was used as the precipitant for $\mathrm{Ca}^{2+}$ ions, as mentioned above. Therefore, the reliability of many reports on $\mathrm{Ca}^{2+}$ ion detection using $\mathrm{K}$-antimonate seemed doubtful. Borgers, in 1987 [12, 21], developed a new method using a combination of $\mathrm{K}$-oxalate and $\mathrm{K}$-antimonate, which we called 2-step chemical precipitation [12, 21]. Bogers and his coworkers used $90 \mathrm{mM} \mathrm{K}$-oxalate followed by $2 \% \mathrm{~K}$ antimonate with osmium tetroxide. In this process, $\mathrm{Ca}^{2+}$ ions in cells become Ca-oxalate as fine precipitates, and $\mathrm{Ca}$-oxalate was replaced by $\mathrm{K}$-antimonate to become $\mathrm{Ca}$ antimonate during the postfixation process. But they did not give adequate physicochemical proof for total replacement of Ca-oxalate, even though they used EDX analysis [21]. We examined the 2-step chemical fixation methods under many fixation conditions, such as conventional immersion fixation, under MWI fixation, and the concentrations of the chemical reagents K-oxalate and $\mathrm{K}$-antimonate. Experimental data were obtained with an electron microscope and analyzed with computerized EDX analysis to differentiate calcium $(\mathrm{Ca})$ and antimony $(\mathrm{Sb})$ and proved their atomic binding ratios (AT, \%), and molecular weight ratios (WT, \%). The data were the same as the values obtained by theoretical calculation, as mentioned in the Introduction and Results. The best results were obtained in the case of 2-step chemical precipitation with MWI fixation at room temperature, using low concentrations in both, $30-40 \mathrm{mM}$ for nervous tissues and $40-$ $60 \mathrm{mM} \mathrm{K}$-oxalate for muscle or others and $1-1.5 \% \mathrm{~K}$ antimonate $[12,19,21,24-26]$. The application of MWI fixation combined with $\mathrm{Ca}^{2+}$ ion detection and computerized EDX or EELS analysis to determine calcium distribution had the advantage of producing rapid and homogeneous infiltration of the chemicals into the depth of the tissues, and produced extremely fine and equal reaction products in the tissue block. Such good fixation for both ultrastructual observations and $\mathrm{Ca}^{2+}$ ion detection were never seen with the conventional immersion fixation method or when a high concentration of reagents was used $[12,19,21$, 24-26, 35].

In the experimental diabetic rat skeletal muscle, there was more calcium in the sarcoplasmic reticula and mitochondria than in controls under the same kind of experimental conditions as ours (Ogawa et al.) [27]. In the developing shell of snail embryos, the atomic binding ratios (AT, \%) between calcium and antimony varied from $0: 1\left(\mathrm{Ca}^{2+}\right.$ ions were not detected) to $1: 2$ (filled with $\mathrm{Ca}^{2+}$ ions). During the calcification process of the snail shell, the ratio of calcium to antimony increased rapidly, until finally only calcium remained. When the calcification process had finished, there were only calcium (crystallized calcium) detected $(1: 0)$, using the 2 -step $\mathrm{Ca}^{2+}$ ion fixation method (Takaichi, et al.) [35].

EDX analysis, can only differentiate the chemical nature of the precipitate but can never get elemental distribution images superimposed on the cellular ultrastructures. But since Ottensmeyer and his coworkers and Mizuhira applied EELS imaging to biological use [1, 4, 29$33 ; 9-10,20-26]$, it has become possible to demonstrate the net elemental EELS digital images superimposed on the cellular ultrastructures using very thin sections, $30 \mathrm{~nm}$ in thickness, either fresh frozen cryoultrathin sections, freeze-substituted sections, or sections fixed in the same way as shown above for the EDX analysis $[6,7,9,10,12$, 20-26, 29-34].

In this report, we have demonstrated net calcium $(\mathrm{Ca})$ and antimony ( $\mathrm{Sb}$ ) or oxygen (O) EELS digital images superimposed on the cell ultrastructures using thin sections treated in the same way as in the EDX analysis under MWI fixation, after typical EELS-spectra of calcium antimonate were recorded. $\mathrm{Ca} \cdot \mathrm{L}, \mathrm{O} \cdot \mathrm{K}$, and $\mathrm{Sb} \cdot \mathrm{M}$ net EELS digital images were demonstrated on the sites where Caantimonate precipitates existed in the skeletal or cardiac muscular sarcoplasmic reticula and endosacs, mitochondria, nucleus and synaptic vesicles, synaptic membranes, and mitochondria of the central nerve terminals. Electron energy-filtered spectroscopic, dark field-like images at about $250 \mathrm{eV}$ are very useful for the understanding of the elemental distribution, even though the unstained sections were extremely thin $(30 \mathrm{~nm})[9,10,20-26]$.

There are several reports on the distribution of calcium ions or relation to the calcium metabolism and the demonstration of Ca-ATPase activity by EELS imaging. Mizuhira used fresh freeze-substituted thin sections of developing bone tissue $[9,10,20,22,23]$, Probst [34] used dichromic acid in phosphoric acid buffer solution for the detection of $\mathrm{Ca}^{2+}$ ions in fish central nerve terminals, and Rahmann and his group [3, 6, 7] mainly used cerium (Ce) for the detection of Ca-ATPase activity in the nerve

Fig. 20. A: Net Ca.L EELS-image of a rat intercostal muscle endosacs (Esk) of sarcoplasmic reticulum (Ser) at $355 \mathrm{eV}$, after background image was subtracted. T: transverse tubule (arrows). B: Net Ca.L EELS-image (blue) superimposed on the dark field-like image at $250 \mathrm{eV}$ (red). Mf: muscle fibrils. C: Net Sb.M image at $590 \mathrm{eV}$ superimposed on the dark field-like image. From images B and C, and the EELS spectrum obtained from the precipitates in the sarcoplasmic reticulum endosacs, which were recognized as Ca-antimonate. (Zeiss EM902A/IBAS).

Fig. 21. A: EELS image of net calcium (Ca.L) of the rat cardiac muscle mitochondria (m) at $355 \mathrm{eV}$ (light blue). Calcium is distributed in the cardiac mitochondria very clearly. Z: Z-band of cardiac myofibril. B: Net Sb-M EELS image at $590 \mathrm{eV}$ (light green). The distribution pattern coincides exactly with that of calcium (A). Zeiss EM-902A/IBAS. 

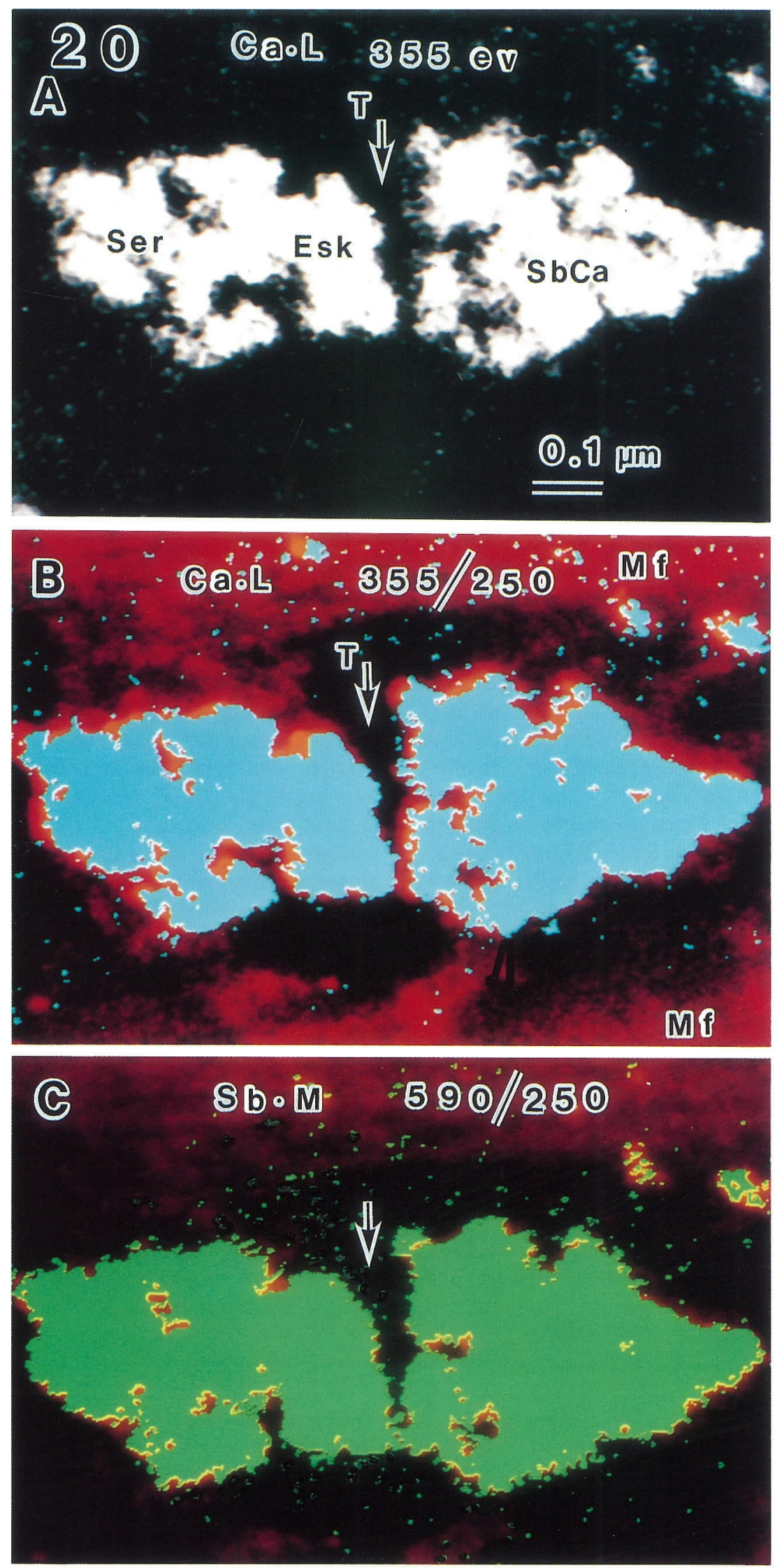

Fig. 20 

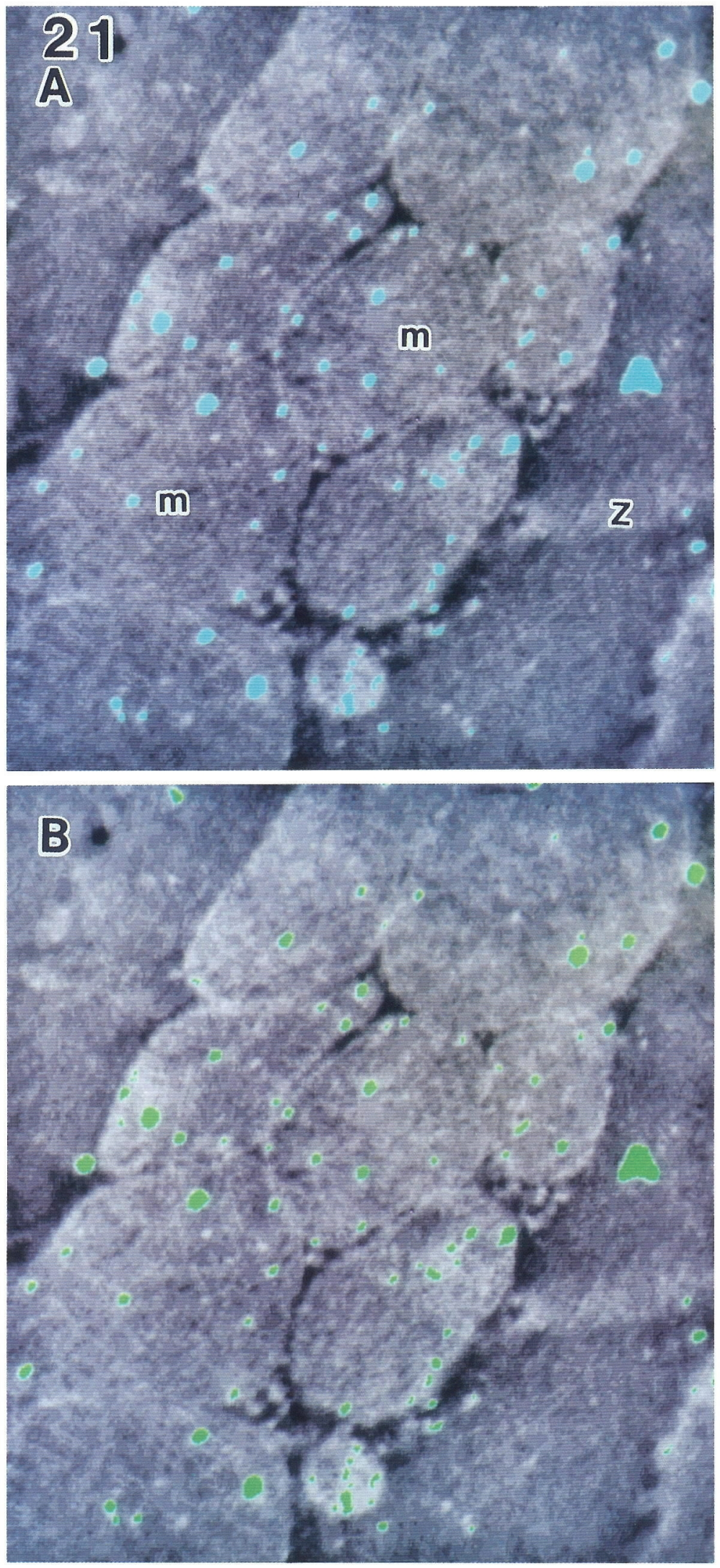

Fig. 21 
terminals instead of lead ions to catch the phosphorus ions for observation with EELS-imaging. The sensitivity of dichromic ions to $\mathrm{Ca}^{2+}$ ions was not very high [12, 21], and this method was not successful in other animal experiments $[12,21,25]$. Rahmann's experiments were not to detect calcium ions but $\mathrm{Ce}$ as the site of Ca-ATPase activity in the central nerve terminals.

We still do not know how many ions aggregate in the core of the precipitates in the cells. Is there an ion path through the membraneous ultrastructures during precipitation? How can we make microwaves penetrate into tissue blocks with reagents $[12,16,18,19,21]$ ? Where are the ions actually located before the precipitation? Is there Liesegang's diffusion phenomenon? These issues are difficult to resolve with the precipitation method, even with MWI/EELS-imaging method. Rapidly frozen cryoultrathin, wet-frozen, or freeze-substituted sections $[9,10$, $20,22,23$ ] should be used to resolve these problems in combination with EELS-imaging, even though there are some technical drawbacks at present.

The use of Fuji imaging plates (IP)/FDL-5000 for EELS produced better quality digital EELS-images than IBAS or other image analyzers. This should be very useful to calculate the quantitative elemental values, or density.

\section{Acknowledgments}

We thank Dr. H. Ozawa, Prof. of Oral Anatomy and Dr. S. Ijiri, Associate Prof. of Oral Anatomy, University of Niigata; Miss E. Takagawa, Carl Zeiss Vision Co., Ltd., Tokyo, and Dr. T. Oikawa, Application \& Research Center, JEOL Co., Ltd. Tokyo, for their technical assistance for EELS analysis. We also thank Dr. R. Goris for proofreading the manuscript.

We regret the untimely death of Dr. Kazuo Ogawa.

\section{References}

1. Bazett-Jones, D. P. and Ottensmeyer, F. P.: Phosphorus distribution in the nucleosome. Sci. 211; 169-170, 1981.

2. Castaing, R. and Henry, L.: Optique électronique. Filtrage magnétique des vitesses en microscopie électronique. Acad. des Sci., Paris, B. 255; 76-78, 1962.

3. Freihöfer, D., Körtje, K. H. and Rahmann, H.: Ultrastructural localization of endogenous calcium in the teleost retina. Histochem. J. 22; 63-72, 1990.

4. Henkelman, R. M. and Ottensmeyer, F. P.: An energy filter for biological electron microscopy. J. Microsc. 102; 79-94, 1984.

5. Kok, L. P. and Boon, M. E.: Microwave Cookbook for Microscopists. Art and Science of Visualization, 3rd Ed., Coulomb Press, Leyden, 1992.

6. Körtje, K. H., Freihöfer, D. and Rahmann, H.: Cytochemical localizationof calcium in the central nervous system of vertebrates. Ultramicrosc. 32; 12-17, 1990.

7. Körtje, K. H., Freihöfer, D. and Rahmann, H.: Cytochemical localization of high affinity $\mathrm{Ca}^{2+}$-ATPase activity in synaptic terminals. J. Histochem. 38(6); 895-900, 1990.

8. Mayers, C. P.: Histological fixation by microwave heating. $J$.
Clin. Pathol. 23; 273, 1970.

9. Mizuhira, V.: Recent advances in biomedical microbeam analysis: EELS-imaging of biomedical specimens. Proc. 4th Asia-Pacific Conf. Workshop on Electron Microsc. Bangkok. 367-374 (special lecture), 1988.

10. Mizuhira, V.: Recent advances in biomedical microbeam analysis: -From EDX to EELS - Imaging analysis of biomedical specimens, especially with respect to calcifying tissue. J. Electron Microsc. 38(Suppl); S142-S146, 1989.

11. Mizuhira, V.: Fixation method for proteins using tannic acid, Current Content, LS. V. 35, \#24, June 15, 1992, p. 9.

12. Mizuhira, V.: New Tissue Fixation and Staining Methods by the Aid of Microwave Irradiation, Gaksai-Kikaku Press, Tokyo (in Japanese), 1993.

13. Mizuhira, V.: Autoradiography for Biomedical Research, -From Macroscopic Autoradiography to Electron Microscopic Autoradiography-, Gakusaikikaku Press, Tokyo, 1993. (in Japanese)

14. Mizuhira, V., Notoya, M. and Hasegawa, H.: In "Autoradiography and Correlative Imaging," ed. by W. E. Stumpf and H. F. Solomon, Academic Press, New York, pp. 497-513, 1995.

15. Mizuhira, V. and Hasegawa, H.: Opening images of synaptic vesicles and calcium localization by means of microwave fixation method, Proc. 12th Int. Cong. Electron Microsc., Seattle, WA, San Francisco Press, 1990, pp.182-183.

16. Mizuhira, V., Hasegawa, H. and Notoya, M.: Demonstration of membrane associated calcium ions of X-ray microanalysis after microwave fixation. J. Clin. Electron Microsc. 24; 5-6, 1990.

17. Mizuhira, V., Notoya, M. and Hasegawa, H.: New tissue fixation method for cytochemistry using microwave irradiation. I. General remarks. Acta Histochem. Cytochem. 23; 501-523, 1990.

18. Mizuhira, V., Hasegawa, H. and Notoya, M.: Microwave fixation and staining method, for biomedical specimens. J. Clin. Electron Microsc. 24; 5-6, 1991.

19. Mizuhira, V., Hasegawa, H. and Notoya, M.: Microwave fixation for histo- and cytochemistry. In "Electron Microscopic Cytochemistry and Immunocytochemistry in Biomedicine," ed. by K. Ogawa and T. Barka, CRC Press, N. W. Fl., USA, 1993, pp. 17-27.

20. Mizuhira, V.: EELS-Imaging method for biological specimens. In "Applications of New Techniques for Electron Microscopy”. 5th EM Summer School, Gakusai Kikaku Press, Tokyo (in Japanese), 1994, pp. 133-146.

21. Mizuhira, V., Hasegawa, H. and Notoya, M.: Localization of calcium in synaptic vesicles. J. Neurosci. Methods. 55; 125136, 1994.

22. Mizuhira, V.: Elemental analysis in cells by the aid of EELSImaging method - especially with respect to the $\mathrm{Ca}^{2+}$ ion distribution-. No. 1, Pure Chemicals Daiichi. 25(2); 14-21, 1995. No. 2, 26(1); 10-17, 1995. No. 3, 26(2); 26-31, 1995 (in Japanese).

23. Mizuhira, V.: EELS-Electron microscopy. The Cell (Saibo) 27(13); 30-38, 1995 (in Japanese).

24. Mizuhira, V.: Microwave fixation method for cytochemistry - for conventional electron microscopy, enzymo- immunocytochemistry, autoradiography and elemental distribution studies by means of EDX and EELS - Imaging analysis - 10th Internat. Congr. Histochem. Cytochem., Proc., pp. 315-316, Technical Seminor 1, Kyoto, Aug. 1996.

25. Mizuhira, V. and Hasegawa, H.: Microwave fixation and localization of calcium in synaptic terminals by means of the $\mathrm{X}$ ray microanalysis (EDX) and electron energy loss spectroscopy (EELS) imaging methods, Brain Res. Bull. 43(1); 53-58, 
1997.

26. Mizuhira, V.: Microwave fixation method for cytochemistry - for conventional electron microscopy, enzymo - immunocytochemistry, autoradiography, elemental distribution studies and staining mehtod using microwave irradiation-, XXIth Internat. Congr. \& Internat. Acad. Pathol. \& 12th World Congr. Acad. Enviroment. Pathol., Budapest, Hungery, Handout, Oct. 1996; J. Europ. Morphol. 34(5); 385-391, 1996.

27. Ogawa, S., Kashiwagi, A., Kikkawa, R. and Shigeta, Y.: Increase of Voltage-sebsitive calcium channels and calcium accumulation in skeletal muscles of Streptozocin-induces diabetic rats. Metabolismm 44(11); 1455-1461, 1995.

28. Ohara, P. T., Wade, C. R. and Lieberman, A. R.: Calcium storage sites in axon terminals and other componentsof intact CNS tissue: studies with a modified pyroantimonate technique. J. Anat. 129; 869-870, 1979.

29. Ottensmeyer, F. P., Bazett-Jones, D. P., Henkelman, R. M., Korn, A.P. and Whiting, R. F.: The imaging of atoms: Its application to the structure determination of biological macromolecules. Chemica Scripta. 14; 257-262, 1978.
30. Ottensmeyer, F. P., Whiting, R. F., Schmidt, R. S. and Clemens, R. S.: Electron microscopy of proteins. A close look at the ashes of myokinase and protamine. J. Ultrastruct. Res. 52; 193-201, 1978.

31. Ottensmeyer, F.P. and Andrew, J. W.: High-resolution microanalysis of biological specimens by electron energy loss spectroscopy and by electron spectroscopic imaging. $J$. Ultrastruct. Res. 72; 336-348, 1980.

32. Ottensmeyer, F.P.: Electron microscopic imaging: Parallel energy filtering and microanalysis in the fixed beam electron microscope. J. Ultrastruct. Res. 88; 121-134, 1984.

33. Ottensmeyer, F. P.: Elemental mapping by energy filtration: Advantages, limitations and compromises. Ann. NY. Acad. Sci. 483; 339-350, 1986.

34. Probst, W.: Ultrastructual localization of calcium in the CNS of vertebrates. Histochemistry. 85; 231-239, 1986.

35. Takaichi, S., Mizuhira, V., Hasegawa, H., Ozawa, H., Ejiri, S. and Notoya, M.: Ultrastructure and calcification of embryonal snail shell. Acta Histochem. Cytochem. (in press) 